\title{
Uso de recursos naturais pelos Índios Piripkura no Noroeste de Mato Grosso: uma análise do Conhecimento Ecológico Tradicional no contexto da política expansionista do Brasil na Amazônia Meridional
}

\author{
The use of natural resources by the Piripkura Indians in the \\ Northwest of Mato Grosso state: an analysis of the Traditional \\ Ecological Knowledge in the context of the Brazilian \\ expansionist politics in the Meridional Amazon \\ Tarcísio da Silva Santos Júnior ${ }^{1}$ \\ Jair Catabriga Candor ${ }^{2}$ \\ ]Ana Suely Arruda Câmara Cabral ${ }^{3}$
}

\begin{abstract}
Resumo
A região correspondente ao interflúvio Tapajós-Madeira, historicamente habitada pelos índios Tupí-Kawahíva, dentre os quais os Piripkura, vem sofrendo profundas transformações na sua paisagem natural, desde a década de 1940. Tal fato gerou a redução das populações indígenas nessa região da Amazônia Meridional, causando profundos impactos negativos na sua organização social, como é o caso dos índios Piripkura, assim como tem reduzido as formações vegetais nativas a fragmentos de diferentes tamanhos na área atualmente interditada pela FUNAI, denominada Terra Indígena Piripkura, com registros confirmados de dois índios homens da referida etnia. O presente trabalho discorre sobre a ocupação do território tradicional dos Piripkura por não-índios, considerando os impactos das ações destes últimos no Conhecimento Ecológico Tradicional dos indígenas (CET-Piripkura) e também no ecossistema em que esse conhecimento se desenvolve. A pesquisa foi realizada com base nos relatórios técnicos, principalmente aqueles produzidos pela Frente de Proteção Etnoambiental Madeirinha-Juruena (FPE-MJ), em incursões a campo para conhecer o meio físico e biótico da TI-Piripkura e, também, na convivência com uma índia Piripkura e com um membro da FPE-MJ, que atua junto aos Piripkura, desde 1999, data do primeiro contato oficial da FUNAI com esses índios. Os resultados demonstram que o CET-Piripkura praticado pelos dois indígenas corresponde à uma fração do original, em função do uso de uma reduzida parcela da biodiversidade e das estratégias empreendidas para acessá-la. Demonstram, ainda, o uso de área mais restrita do território tradicional indígena, o que

\footnotetext{
${ }^{1}$ Doutor em biologia, pesquisador na Universidade Federal de MAto Grosso.

2 Coordenador da Frente de Proteção Etnoambiental Madeirinha-Juruena Fundação Nacional do Índio.

${ }^{3}$ Doutora em Linguística, professor associado na Universidade de Brasília, Bolsista em produtividade científica, PQ1D, Coordenadora do Laboratório de Línguas e Literaturas Indígenas.
} 
está relacionado às ações de não-índios que interferem diretamente na dinâmica de uso e ocupação do espaço geográfico pelos índios. A reprodução física e cultural dos Piripkura depende da prática do CET-Piripkura, a qual está intrinsicamente relacionada à qualidade ambiental do ecossistema, situação que não condiz com a política de expansão econômica em voga na Amazônia Meridional. A sobrevivência dos Piripkura depende de um território livre de influências antrópicas de não-índios.

Palavras-chave: Piripkura, Território tradicional, Impactos ambientais, Sobrevivência de povos indígenas isolados

\section{Abstract}

The region corresponding to the interplay Tapajós-Madeira rivers, historically inhabited by the Tupi-Kawahíva Indians, among them the Piripkura, has undergone deep transformations in its natural landscape since the 1940s. This fact led to the reduction of the indigenous populations in this region of the Amazon, causing negative impacts in their social organization, as it has been the case of the Piripkura Indians, as well as well as to the reduction of native plant formations to fragments of different sizes within which there is one, currently interdicted by FUNAI, named the Piripkura Indigenous Land, based on confirmed records of Two Indian men of that ethnic group. The present work deals with the occupation of the traditional territory of the Piripkura by non-Indians, considering the impacts of the latter's actions on the Traditional Ecological Knowledge of the Indians (CET-Piripkura), and also on the ecosystem where this knowledge develops. The research was carried out based on (a) the content of the technical reports produced mainly by the Madeirinha-Juruena Ethno-Environmental Protection Front (FPE-MJ), during field trips aiming the description of the physical and biotic environment of TI-Piripkura, and (b) the reports made by the Piripkura woman and by a member of the FPE-MJ who has been with the Piripkura since 1999, the date of the first official contact carried out by FUNAI. The results of the present study show that the CET-Piripkura practiced by the two Indians corresponds to a portion of their original activities, due to the use of a small part of the biodiversity as well as to the strategies undertaken to access it. The results also demonstrate the use of a more restricted area of their traditional territory which in tour is related to the actions of non-Indians that directly interfere in the dynamics of use and occupation of the geographic space. The physical and cultural reproduction of the Piripkura depends on the practice of the CET-Piripkura and it is intrinsically related to the environmental quality of the ecosystem, a situation that is not in line with the policy of economic expansion in vogue in Southern Amazonia. The survival of the Piripkura depends on a free territory of anthropic influences of non-Indians.

Keywords: Piripkura, Traditional territory, Environmental Impacts promoted by outsiders, Survival of Isolated Indigenous people

\section{Introdução}

A macrorregião onde se insere a Terra Indígena Piripkura (TI-PRK) ${ }^{4}$ se

\footnotetext{
${ }^{4}$ A Terra Indígena Piripkura, com 242.500 hectares de extensão, foi declarada por meio da Portaria de Restrição de Uso (Número 1.154) expedida pela presidência da FUNAI em 30/09/2008. Essa portaria tem sido renovada bianualmente até que sua regularização
} 
constitui em um remanescente de floresta da Amazônia Meridional que desde os anos 40 está sendo submetida a crescentes impactos negativos diretos e indiretos ocasionados pelos contínuos incentivos do governo brasileiro ao avanço das frentes de expansão econômica (EPE 2011: 97 a 170; SDS/AM 2010: 118 a 140). Sua ocupação por não-índios começou a ser intensificada com a penetração e permanências dos "soldados da borracha" entre as décadas de 40 e 60, prosseguindo nos anos $70 \mathrm{com}$ os incentivos financeiros da SUDAM ${ }^{5}$ para implantação de empreendimentos agropecuários. Posteriormente, foram concebidos e implantados os projetos POLONOROESTE ${ }^{6}$, PRODEAGRO $^{7}$ e Brasil em Ação ${ }^{8}$ contribuindo para a abertura de rodovias (BR-364, BR-230, MT-206 e RO-205) e consolidação de municípios (Colniza, Rondolândia, Apuí) e de localidades (Vila Guariba, Vila Guatá e Santo Antônio do Matupi) que, por sua vez, ainda têm economia baseada na exploração de madeira, agropecuária extensiva e garimpo (Figura 1) (EPE 2011: 97 a 170). Na atualidade, o incentivo à continuidade da ocupação da Amazônia Meridional está sendo sustentado por recursos financeiros diretamente vinculados ao $\mathrm{PAC}^{9}$, que no noroeste do Mato Grosso vem implementado empreendimentos hidrelétricos nos rios Teles Pires, Juruena, Aripuanã e também promovendo a melhoria da malha viária (Verdum 2012).

fundiária seja concluída.

${ }^{5}$ A SUDAM, Superintendência do Desenvolvimento da Amazônia foi criada pela lei $\mathrm{n}^{\circ}$ 5.173, de 27 de outubro de 1966. Os incentivos fiscais em favor da instalação de atividades econômicas na Amazônia foram concedidos por intermédio da lei $\mathrm{n}^{\circ}$ 5.174.

${ }^{6} \mathrm{O}$ projeto POLONOROESTE, Programa Integrado de Desenvolvimento do Noroeste do Brasil, foi executado nos anos 80 com recursos do governo brasileiro e Banco Mundial, sob a coordenação da Superintendência do Desenvolvimento do Centro Oeste. O foco de sua atuação foi no eixo da rodovia BR-364 entre Cuiabá (MT) e Porto Velho (RO), mas sua implementação abriu espaço para intensificar a ocupação no seu eixo Leste-Oeste por não-índios.

7 O PRODEAGRO, Programa de Desenvolvimento do Agronegócio, começou a ser executado na década nos anos 90, sob a coordenação conjunta de Estados, Governo Federal e o Banco Mundial. O foco de sua atuação foi promover a implementação de atividades relacionadas ao agronegócio.

${ }^{8}$ O Programa Brasil em Ação foi lançado em agosto de 1996 para dar prioridade a um conjunto de 42 empreendimentos voltados para a promoção do desenvolvimento sustentável do País e estrategicamente escolhidos pela capacidade de induzir novos investimentos produtivos e reduzir desigualdades regionais e sociais.

${ }^{9}$ Programa de Aceleração do Crescimento - criado em 27 de janeiro de 2007, através do decreto 6.025, com foco em articula projetos de infraestrutura públicos e privados e medidas institucionais para aumentar o ritmo de crescimento da economia. Seus principais objetivos são modernizar a infraestrutura, melhorar o ambiente de negócios, estimular o crédito e o financiamento, aperfeiçoar a gestão pública e elevar a qualidade de vida da população, funcionar como um instrumento de inclusão social e de redução das desigualdades regionais. 
Figura 01. Contexto de inserção da Terra Indígena Piripkura na Amazônia Meridional com foco no noroeste do estado de Mato Grosso.10
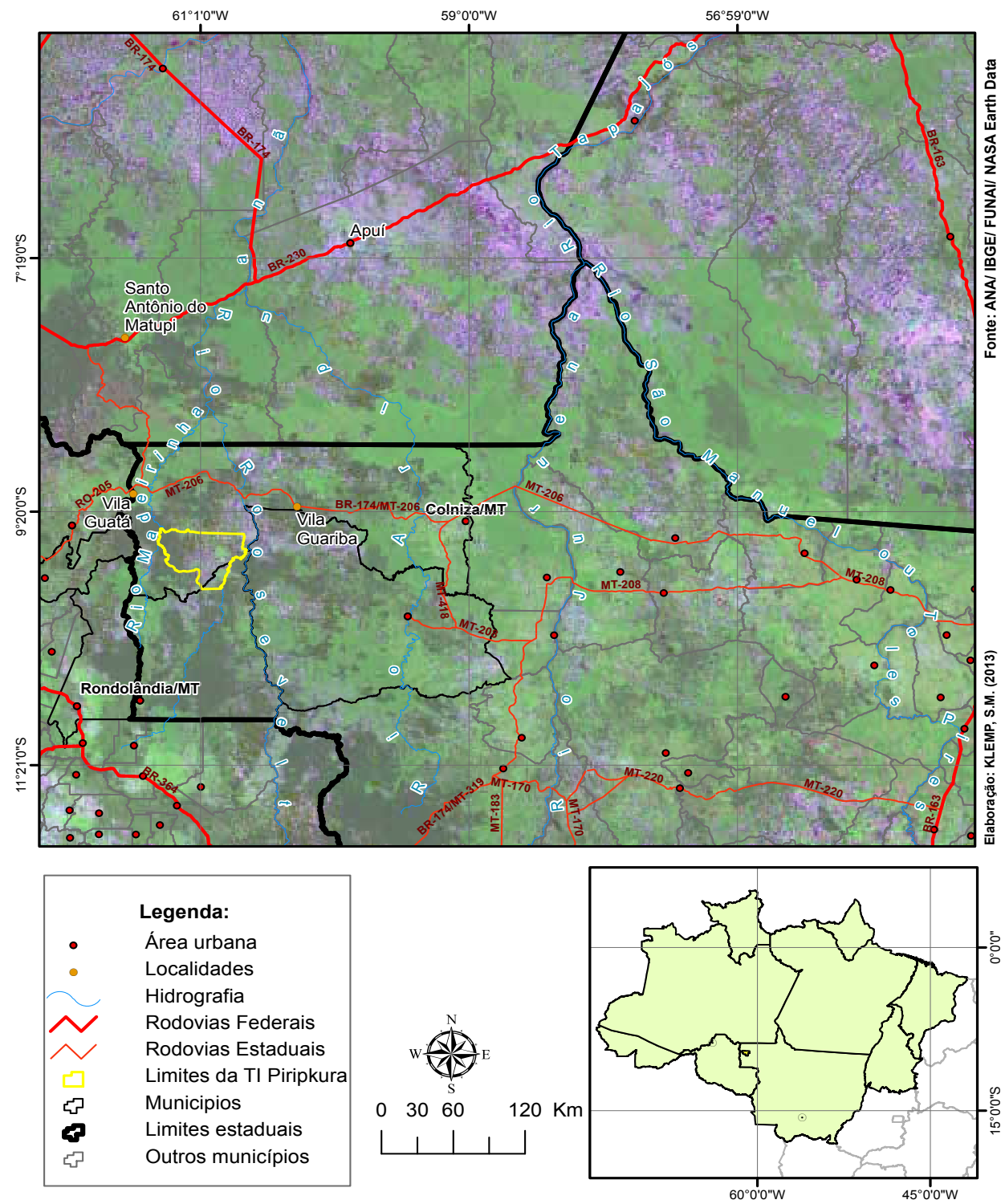

${ }^{10}$ Nota: mapa gerado a partir de imagens Modes datadas de XX. A cor lilás denota a presença de solo exposto, seja de origem natural ou antrópica. Na TI Piripkura a cor corresponde, em sua maioria, aos topos de serra que se apresentam desnudos na estação seca por serem cobertos por vegetação de baixo porte ou por apresentar maior incidência de espécies vegetais caducifólias. 
Em relação aos indígenas, para esta mesma macrorregião da Amazônia, há documentos datados do século XVI, como reporta Menendez (1992), comprovando sua presença no interflúvio entre os rios Madeira e Tapajós, incluindo o Juruena e seus principais afluentes (Menéndez 1992). O autor observa que o nome Kawahíva ${ }^{11}$ - grupo linguístico da família Tupí-Guaraní a qual pertencem os Piripkura ${ }^{12}$ - é citado pela primeira vez na literatura em 1847, e apresenta a rota de migração dos mesmos entre os séculos XVII e XIX. A ocupação dos Kawahíwa é identificada acima da foz do rio Arinos, no Juruena, seguindo pela margem direita deste, de onde, após cruzá-lo, continua rumo ao interflúvio entre os rios Machado e Roosevelt, ambos afluentes da margem direita do rio Madeira. Esta informação é corroborada pela presença dos índios isolados "Kawahíva do Rio Pardo" ${ }^{13}$ entre os rios Juruena e Aripuanã e dos Pirikura entre o Machado e o Roosevelt (afluente da margem esquerda do Aripuanã). Ademais, há ainda extenso registro arqueológico e estudos linguísticos que comprovam a presença dos Kawahíva ${ }^{14}$ e de outros povos do tronco Tupí em uma extensão territorial que abrange a região norte dos estados de Rondônia e Mato Grosso (Miller 2009; Rodrigues 2000: 1598).

A problemática dos impactos socioambientais negativos para os Piripkura emerge oficialmente como questão a ser tratada pela Fundação Nacional do Índio (FUNAI) ${ }^{15} \mathrm{em}$ 1984, a partir de estudos iniciados pela Operação Amazônia Nativa $(\mathrm{OPAN})^{16}$, mas desde 1890 há relatos de conflitos entre os Kawahíwa e não-índios (Azanha 2006: 8 a 25). As informações coligidas nessas referências permitem dizer que os massacres sofridos pelos Piripkura contribuíram fortemente para

${ }^{11}$ Rodrigues, em seu artigo Relações internas na família Tupí-Guaraní (Revista de Antropologia, 27/28, 1984-85, p. 33-53. São Paulo), se refere ao complexo Tupí-Kawahíb, como constituído das línguas "Tupí do Machado, Pawaté, Wiraféd etc.", classificadas por ele como pertententes ao subramo VI da família linguística Tupí-Guaraní.

${ }^{12} \mathrm{O}$ nome Piripkura corresponde à denominação atribuída ao grupo Kawahíwa, em pauta neste estudo, pelos índios da etnia Gavião. Desde então, este grupo de índios isolados passou a ser tratado oficialmente como Piripkura.

${ }^{13}$ Grupo de índios isolados do coletivo Kawahíwa que habita a Terra Indígena Kawahiva do Rio Pardo, localizada no interflúvio entre os rios Aripuanã e Guariba no estado de Mato Grosso.

${ }^{14}$ Para o termo Kawahíwa, Cabral (2010) propõe a etimologia composta de kaw + hiw-a (caba+brabo-caso.argumentativo), com base em pesquisa realizada junto aos Asuriní do Tocantins, aos Kamaiura e aos Zo'é. O composto Kawahiwa é usado nessas línguas com referencia a índios 'brabos', que vivem no mato. A raiz nominal -ahiw (-ahi em Zo'é) pode ser traduzida por 'ruim', 'difícil', 'brabo'.

${ }^{15}$ Instituição vinculada ao governo brasileiro que trata oficialmente das questões indígenas no País.

${ }^{16}$ A sigla OPAN, Operação Amazônia Nativa, antes de 1997, correspondia ao nome Operação Anchieta. 
desestruturar sua organização social e os levaram a estabelecer contato com pessoas vinculadas aos empreendimentos agropecuários instalados no interior de seu território tradicional a partir da década de 1970. Na atualidade, a Frente de Proteção Etnoambiental Madeirinha-Juruena (FPE-MJ) ${ }^{17}$ tem confirmada a existência de três sobreviventes, sendo uma mulher (Rita Piripkura) e dois homens (Tikum e Monde'i). Rita vive fora de seu território tradicional desde 1980, mas os outros, com os quais a FPE-MJ fez contato pela primeira vez, em maio de 1989, ainda vivem na TI-PRK, arredios ao contato com a sociedade envolvente ${ }^{18}$.

Informações colhidas junto a Rita, tendo como referência o tempo em que ela vivia no seu território, permitem dizer que, entre 1960 e 1980, os Piripkura somavam aproximadamente 19 pessoas, por sua vez remanescentes de uma família extensa que sobreviveu a um massacre perpetrado por não-índios antes do nascimento de Rita. Tal família se constituía de dois subgrupos distintos que mantinham relações amigáveis entre si, mas somente o progenitor de um dos subgrupos ao qual pertenciam os dois homens, ainda dominava a técnica de confecção de arco e flecha. Os relatos de Rita quanto ao número de remanecentes Piripkura foram reforçados pela OPAN, durante expedição realizada no território em 1986; guiados por Rita a equipe encontrou duas malocas, sendo uma com dimensões adequadas para abrigar 15 pessoas e outra dez pessoas. Um ponto adicional que corrobora informações relativas ao maior número de indígenas antes de 1985 é o fato de a OPAN ter tido contato no território com pelo menos dois outros indígenas homens, distintos daqueles que continuam habitando a TI-PRK.

No transcorrer das atividades da FPE-MJ na região, desde o contato com os dois Piripkura em 1989, os vestígios encontrados são atribuídos às ações da presença dos Piripkura. No entanto, não há subsídios para desconsiderar a existência de outros sobreviventes, além dos dois homens da referida família extensa e também de outros Piripkura, seja habitando a TI-KRP ou remanescentes de floresta nativa bem conservados e sem intensa ocupação/ visitação de não-índios no interflúvio Roosevelt-Madeirinha. Isto porque os estudos realizados pela FPE-MJ nessa região não são conclusivos. Em verdade, quando se tem como parâmetro o atual modo de vida, tanto dos Piripkura quanto

\footnotetext{
${ }^{17}$ A FPE-MJ, recebeu a denominação de Frente de Proteção Etnoambiental Madeirinha Juruena a partir de 2012, mas entre os anos de 2012 e 2000 era denominada de Proteção Etnoambiental Madeirinha e entre 2000 e 1987 de Frente de Frente de Contato Madeirinha. ${ }^{18}$ A OPAN atuou na região entre os anos de 1985 e 1987. Entre os anos de 1988 e 1992 as atividades na região foram realizadas pela FPE-MJ. Entre 1992 e 1997 a FPE-MJ foi deslocada para o Pontal dos Apiaká. A partir de 1998 a FPE-MJ retomou suas atividades na TI-PRK, mas na atualidade, divide seu tempo e recursos entre atividades de fiscalização e monitoramento de índios isolados na T.I Kawahíwa do Rio Pardo e T.I. Apiakás do Pontal e Isolados
} 
dos Kawahíva do Rio Pardo, frente ao conjunto de impactos ambientais e sociais negativos gerados em sua cultura e território, é plausível considerar que haja outros sobreviventes. Tal perspectiva é reforçada pelo registro de aumento populacional entre os Kawahíva do Rio Pardo e também pelas 11 referências da presença de índios isolados na área de atuação da FPE-MJ ${ }^{19}$ (Jair Candor, comunicação pessoal).

O modo de vida Piripkura que tem garantido sua sobrevivência pode ser compreendido como resultado da prática do seu conhecimento ecológico tradicional, doravante CET, definido por Berkes, Folke and Gadgil (1995) como:

"conjunto cumulativo de conhecimentos e crenças vinculadas às relações entre os seres vivos (inclusive humanos) e entre estes com seu ambiente, por sua vez mantidos entre as gerações por meio da transmissão cultural".

A partir desta definição, subtende-se que o CET-Piripkura envolve o conhecimento do espaço geográfico, a localização dos recursos naturais no mesmo, assim como as interações bióticas e abióticas entre os recursos da fauna e da flora e destes com o ambiente físico (clima, hidrografia, relevo e solos). A compreensão deste espaço na perspectiva do funcionamento do ecossistema para se obter os recursos necessários à sobrevivência - por exemplo, saber se um fruto é palatável, onde se encontra localizado e quando vai estar disponível para consumo - demanda, entre outros, observação, experimentação, aprendizado e transmissão de conhecimento (Berkes, Folke and Gadgil 1995). Esta sequência de ações necessita de repetições, o que somente ocorre quando um grupo de pessoas se estabelece em determinado lugar, como tem sido o caso dos Kawahíwa, com respeito ao seu território tradicional (Menendez 1992).

O presente trabalho de pesquisa discorre sobre o CET-Piripkura, elaborado a partir de informações colhidas junto a Rita Piripkura e também de vestígios catalogados e qualificados pela FPE-MJ entre 1989 e 2013. Seu desenvolvimento está pautado na premissa de que o histórico de contato dos Piripkura com membros da sociedade nacional e também o atual contexto de pressões antrópicas na TI-PRK e seu entorno, impôs e continua impondo modificações ao CET-Piripkura quanto ao uso e ocupação do espaço geográfico e de seus recursos naturais. Assim, a pesquisa é desenvolvida no contexto da resiliência ecológica do ecossistema e seu uso sustentável, conforme Berkes and Folke (2000). Esses autores consideram o ecossistema na perspectiva

\footnotetext{
${ }^{19}$ A Portaria $N^{\circ} 1.509$ da Presidência da FUNAI (20/11/2012) estabelece como área de jurisdição da FPE-MJ municípios localizados nos estados de Mato Grosso (Alta Floresta, Apiacás, Colniza, Rondolândia, Aripuanã e Cotriguaçu), Amazonas (Novo Aripuanã, Apuí e Maués) e Pará (Jacareacanga).
} 
holística proposta por Odum $(1988)^{20}$, inserindo nela o componente "sistema social", e no que tange à resiliência ecológica, adotam as abordagens de Holling (1973; 1986) e Holling et al. (1995). Nesses trabalhos, partindo do conceito elaborado em $1973^{21}$, ao qual se adicionou a "imprevisibilidade de ocorrência de distúrbios" em $1986^{22}$, a resiliência ecológica é compreendida com ênfase nos distúrbios ou perturbações que podem mudar o ecossistema de um estado de equilíbrio dinâmico para outro (Holling et al. 1995). Neste sentido, Berkes and Folke (2000) entendem que a resiliência pode ser mensurada pela magnitude ou escala dos distúrbios que podem ser absorvidos pelo ecossistema, antes que ocorram mudanças em sua estrutura, ocasionadas por mudanças nas variáveis e processos que controlam o funcionamento do próprio ecossistema. Isso é de extrema relevância, pois de forma similar a outros CET, o CET-Piripkura também se desenvolve no ecossistema e se baseia na coevolução temporal e espacial de práticas de uso sustentável da biodiversidade, sem a qual, a manutenção da qualidade ambiental do ecossistema e, consequentemente, a sobrevivência dos Piripkura são improváveis (Berkes, Folkes and Gadgil 1995; Hooper et al. 2005).

No contexto do parágrafo anterior e também considerando as influências antrópicas de não-índios já mencionadas, o questionamento que se faz nesta pesquisa é relativo à capacidade de adaptação dos Piripkura aos novos cenários impostos à TI-PRK e seu entorno, tendo como objeto de análise o CET-Piripkura, conforme sumarizado na figura 02. Os resultados da pesquisa mostram que a expansão econômica regional, baseada no uso exaustivo de recursos naturais, retroalimenta um ciclo de degradação ambiental, que gera redução da biodiversidade e da resiliência ecológica. A continuidade do ciclo muda o estado de equilíbrio do ecossistema (ecossistema TI-PRK (A)) para outro (ecossistema TI-PRK (B)), quando o primeiro não consegue absorver mais impactos ambientais negativos (resiliência ecológica). $\mathrm{O}$ resultado deste processo é que o novo estado de equilíbrio do ecossistema pode não ser viável à reprodução física dos Piripkura, na medida em que a nossa premissa é de que a CET-Pirikura depende, sumariamente, do manejo adaptativo da biodiversidade distribuída na heterogeneidade espacial que compõe a TI-PRK. Enfim, no atual contexto político e socioeconômico, a compreensão do uso e ocupação da TIPRK pelos Piripkura é relevante como forma de contribuir para a salvaguarda

\footnotetext{
${ }^{20}$ Qualquer unidade, delimitada no tempo e no espaço, que abranja todos os organismos que funcionam em conjunto (a comunidade biótica) interagindo com o ambiente físico de tal forma que o fluxo de energia produza estruturas bióticas claramente definidas e uma ciclagem de materiais entre as partes vivas e não-vivas.

${ }^{21}$ Diz respeito à persistência das relações dentro de um sistema e é medida pela capacidade do mesmo de absorver mudanças em suas variáveis, controlando-as.

${ }^{22}$ Característica comum aos ecossistemas que diz respeito ao surgimento de mudanças imprevistas no decorrer do uso de um ou mais de seus recursos.
} 
de seus direitos, conforme preconizado pelos artigos 230 e 231 da Constituição Federal do Brasil de 1988, pois seu território tradicional ainda não está assegurado pelo Estado Brasileiro e, na atualidade, continua sob ameaça da expansão econômica.

Figura 2. Representação esquemática ilustrando como as atividades antrópicas de não-índios afetam a resiliência ecológica da TI-PRK como ecossistema, podendo alterar seu atual estado de equilíbrio, composto majoritariamente de formações florestais em bom estado de conservação. A figura também ilustra as principais características do CET-Piripkura e questiona se sua manutenção como estratégia de conservação conseguirá se viabilizar em outros estados de equilíbrio do ecossistema.

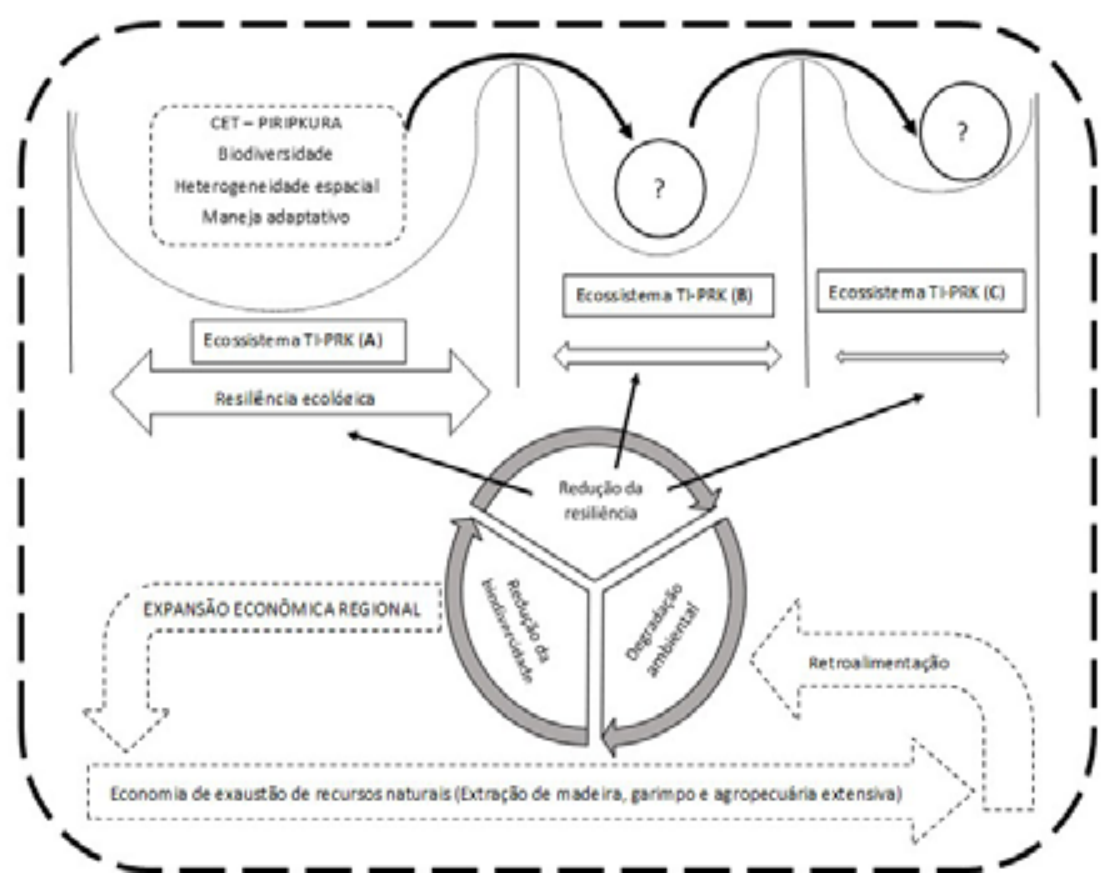

\section{Objetivos e metodologia de desenvolvimento do trabalho}

A pesquisa que fundamentou este artigo teve como objetivo principal estudar o uso e ocupação da TI-PRK pelos Piripkura no contexto da figura 2, especificamente no que diz respeito ao conhecimento dos tipos de recursos naturais disponíveis e às estratégias de obtenção dos mesmos como forma de elucidar o CET-Piripkura. O estudo requeriu acesso a informações sobre o meio físico e biótico da TI-PRK para conhecer minimamente sua estrutura e funcionamento como ecossistema. A compreensão do CET-Piripkura na perspectiva do ecossistema, por sua vez, necessitou de análise dos dados 
relativos à sua prática no tempo (estações climáticas) e no espaço geográfico.

Para caracterizar os meios físico (clima, relevo, hidrografia e solo) e biótico (fauna e flora) da TI-PRK e seu entorno foi realizada consulta ao volume 16 (Folha SC.20 Porto Velho) do Projeto RADAMBRASIL e ao estudo de Avaliação Ambiental Integrada da Bacia do rio Aripuanã (Brasil 1978; EPE 2011). Informações adicionais sobre a fauna e flora foram obtidas por meio de entrevista junto à índia Piripkura, quando de sua participação com os autores deste trabalho no Estudo de Fundamentação Antropológica e Etnoambiental da TI-PRK, em 2010. No âmbito deste estudo, em outubro do mesmo ano, também foi realizado sobrevoo de cerca de seis horas para avaliar a integridade ambiental de todo o limite da TI-PRK, especificamente quanto à presença de desmatamentos, queimadas, estradas e outros usos do espaço por não-índios.

O estudo propriamente dito do uso e ocupação da TI-PRK foi desenvolvido com base na análise dos relatórios técnicos produzidos pela OPAN e FPE-MJ entre 1984 e 2013. A metodologia consistiu em coligir dados destes relatórios e em elaborar uma tabela com os vestígios catalogados durante as expedições, qualificando-os quanto à localização por igarapé, data de registro, idade, época em que foi utilizado, recurso natural envolvido, indicação de como esse recurso foi utilizado e da estratégia para acessá-lo. O entendimento da "estratégia para acessar os recursos" também envolveu análise de relações entre vestígios catalogados em uma mesma e/ou entre expedições, pois em alguns casos não foi possível qualificá-los diretamente, ou seja, a compreensão de determinados vestígios foi entendida apenas no contexto de uma análise global das expedições. Após esta qualificação prévia, somente os dados obtidos entre 2007 e 2013 foram efetivamente utilizados para uma análise da dinâmica de uso e ocupação da TI-PRK pelos Piripkura, devido à periodicidade de atuação em campo da FPE-MJ. Entretanto, todos os dados obtidos entre 1985 e 2013 são considerados nesta pesquisa para a compreensão do histórico de uso e ocupação do território tradicional Piripkura.

Por fim, para compor o entendimento do CET-Piripkura e poder contextualizálo no histórico de ocupação da TI-PRK e de sua estrutura e funcionamento como ecossistema, o presente trabalho valeu-se do conhecimento e vivência de Rita Piripkura e Jair Candor. Ambos são aqui considerados como consultoreschave, na medida em que a primeira é uma Piripkura e detentora da cultura de seu povo; o segundo atua na equipe da FPE-MJ desde 1989, data do primeiro contato com os indígenas Tikun e Monde'í.

\section{Caracterização dos meios físico e biótico na TI-PRK}

\section{Clima, relevo e hidrografia}

Na TI-PRK predomina o clima do tipo Am (Classificação de Köppen), 
ou seja, quente e chuvoso ao longo do ano com um período de seca curto. A disponibilidade de chuva, cuja média anual histórica é de $2.450 \mathrm{~mm}$ e sua distribuição heterogênea ao longo do ano determina duas estações climáticas: o "verão" e o "inverno". A primeira, que vai de maio a setembro, corresponde ao tempo da seca, chegando a registrar $0 \mathrm{~mm}$ em julho, e a segunda, que vai de outubro a março, corresponde ao tempo da chuva, época em que as precipitações ocorrem em maior quantidade, podendo atingir $500 \mathrm{~mm}$ em janeiro e fevereiro. Esta discrepância pluviométrica, aliada ao relevo e a geologia locais, é fator preponderante para gerar déficit hídrico no solo e forte oscilação do nível da água da hidrografia na TI-PRK.

A temperatura média anual das máximas oscila entre $31^{\circ}$ e $33^{\circ} \mathrm{C}$ e a das mínimas entre $20^{\circ}$ e $22^{\circ} \mathrm{C}$. Os menores e maiores valores de temperatura são registradas nos meses de julho e agosto, período em que as mínimas oscilam entre $18^{\circ}$ e $20^{\circ} \mathrm{C}$ e as máximas entre $35^{\circ}$ e $40^{\circ} \mathrm{C}$ (INMET 2013; Brasil 1978).

O relevo da região esta localizado no domínio da unidade geomorfológica Superfície Rebaixada do Norte que localmente é composta pelas Baixas Cadeias de Montanhas do Sul da Amazônia e pela Superfície Dissecada do Alto Rio Madeira (Moreira e Vasconcelos 2007: 25-40; Brasil 1980). O conjunto se caracteriza por apresentar relevo com cotas altimétricas oscilando entre 150 e 250 metros e com elevações residuais, como por exemplo a Serra do Repartimento (320 metros) e a Serra da Caçapa (355 metros). Assim, partindose do topo de uma destas serras em direção a qualquer ponto de menor elevação dentro dos limites da TI-PRK, o relevo se apresenta, primeiramente, como montanhoso (topo do morro), depois forte ondulado (encostas) e, em seguida, por uma paisagem com predominância de formas suaves onduladas (rampas colinosas) e onduladas (colinas), alternadas por vales, que podem se apresentar com fundo oscilando entre estreito (declives em $\mathrm{V}$ ) e extenso, neste último caso com aparência tendendo a ser plana.

A TI-PRK esta localizada no interflúvio dos rios Madeirinha e Roosevelt, ambos afluentes da bacia do rio Madeira. A hidrografia do perímetro da TIPRK é composta por inúmeros igarapés, todos com suas nascentes localizadas a diferentes posições da Serra do Repartimento. Ao sul desta, os igarapés que têm suas nascentes a oeste (Seis contos jakaréa, Rosinha, Rosa) drenam suas águas para o rio Madeirinha, já aqueles com nascentes a leste (Índios Kurumía rekwába, Repartimento Urukutýwuhúa, Paca Iãpetéga, Garça do índio Iakahukába e Garça do branco Yrytýbuhúa) drenam suas águas para o rio Branco Paraná que tem sua foz no rio Roosevelt. Ao Norte da mesma serra, os igarapés do Veado e da Serra drenam suas águas para o rio Madeirinha, enquanto que os igarapés das Panelas Arapary'úwa e Duelo Tatápãja drenam suas águas para o rio Roosevelt. No período da seca, somente se mantém com água o leito principal dos igarapés do Índio, Repartimento, Duelo, Veado, Rosa e Seis Contos (Figura 3). 


\section{Solos e formações vegetais}

Os solos e as formações vegetais que compõem a TI-PRK tendem a estar associados entre si e ao relevo (Brasil 1978). Onde há oscilação entre ondulado (Rampas colinosas) e suave ondulado (Colinas), os Argissolos VermelhoAmarelo Álico predominam sobre os Latossolos Vermelho-Amarelo Álico e a cobertura vegetal é do tipo Floresta Ombrófila Aberta (FOA). Nas regiões em que o relevo varia de aspecto entre suave ondulado (Colinas) e plano (Vales extensos), os Latossolos predominam sobre os Argissolos Vermelho-Amarelo Álico e a cobertura vegetal é do tipo Floresta Ombrófila Densa (FOD). Esta mesma formação vegetal predomina nos Neossolos Litólicos Distróficos (NLD) que ocorrem nos locais onde o relevo é fortemente ondulado (Vales em V) ou montanhoso (Topos de morro). Onde os neossolos são rasos, expondo a rochamãe, a cobertura vegetal é dominada por formações campestres e savânicas.

Figura 3. Hidrografia e relevo da Terra Indígena Piripkura.

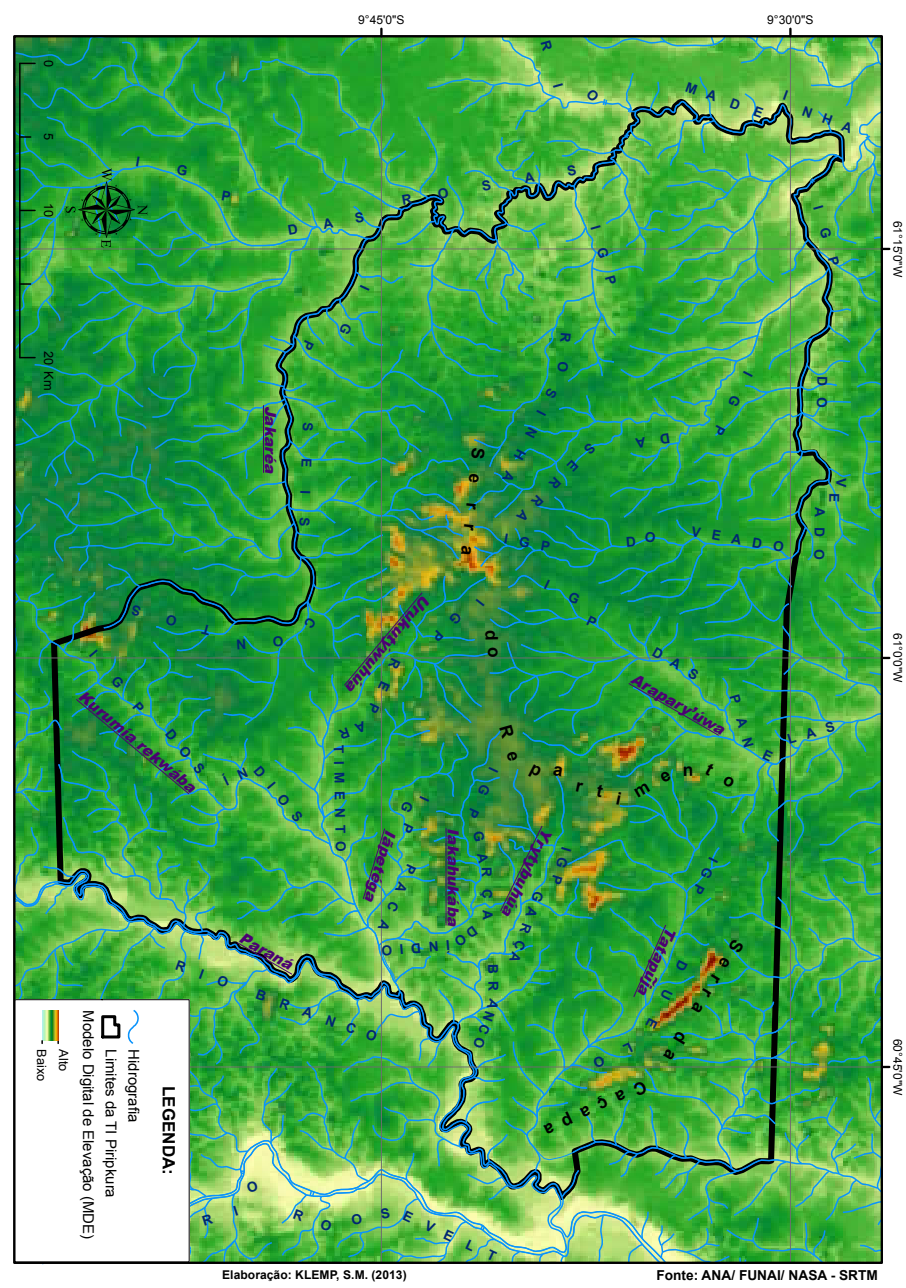


Os dois tipos de floretas ombrófilas, apesar das tendências relativas à sua distribuição no espaço, apresentam-se in loco sem uma distinção nitidamente marcada entre as mesmas. Mesmo assim, é possível mencionar que a FOD é mais comum nas partes mais elevadas das colinas, enquanto a FOA é mais comum nos vales planos de interflúvio de igarapés, onde há predomínio de palmeiras (Floresta Ombrófila Aberta com Palmeiras), e também nas encostas dos morros e dos vales, onde há maior ocorrência de cipós (Floresta Ombrófila Aberta com Cipós). Neste sentido, a partir da figura 3, é possível descrever de forma genérica, que as áreas com tonalidades de cor verde escuro correspondem a locais com predominância de FOD, que as de cor verde claro e de cor creme denotam as regiões com maior incidência de FOA, e que aquelas com tonalidades entre o laranja e o amarelo representam ocorrências de formações savânicas.

\section{Integridade ambiental, diversidade florística e faunística na TI-PRK}

A partir do sobrevoo realizado em 2010, e também da análise visual de imagens do Google Earth datadas de 2013, é possível dizer que a TI-PRK e seu entorno imediato se apresentam em bom estado de conservação ambiental, mas que aproximadamente $5 \%$ de seu território apresenta impactos negativos consequentes da ocupação do território indígena por não-índios (Figura 4). Este cenário, entretanto, contrasta fortemente com a predominância de uma paisagem fragmentada e degradada, resultante da conversão das florestas nativas em pastagem ${ }^{23}$, que se faz presente no sul (área urbana de Rondolândia e extensão de seu entorno), no norte e noroeste (eixo da MT-206 entre Colniza, Distrito de Guariba e Vila Guatá no estado de MT) e oeste (área urbana de Colniza e extensão de seu entorno) da TI-PRK.

\footnotetext{
${ }^{23}$ A conversão de florestas nativas em pastagens é, via de regra, a "etapa final" do ciclo da expansão econômica na Amazônia Meridional, que normalmente se inicia com atividades de garimpo e extração de madeira.
} 
Figura 4. Ilustração das áreas impactadas por atividades antrópicas de nãoíndios na Terra Indígena Piripkura e seu entorno imediato. As áreas de cor laranja correspondem a locais onde foi feita supressão da floresta.

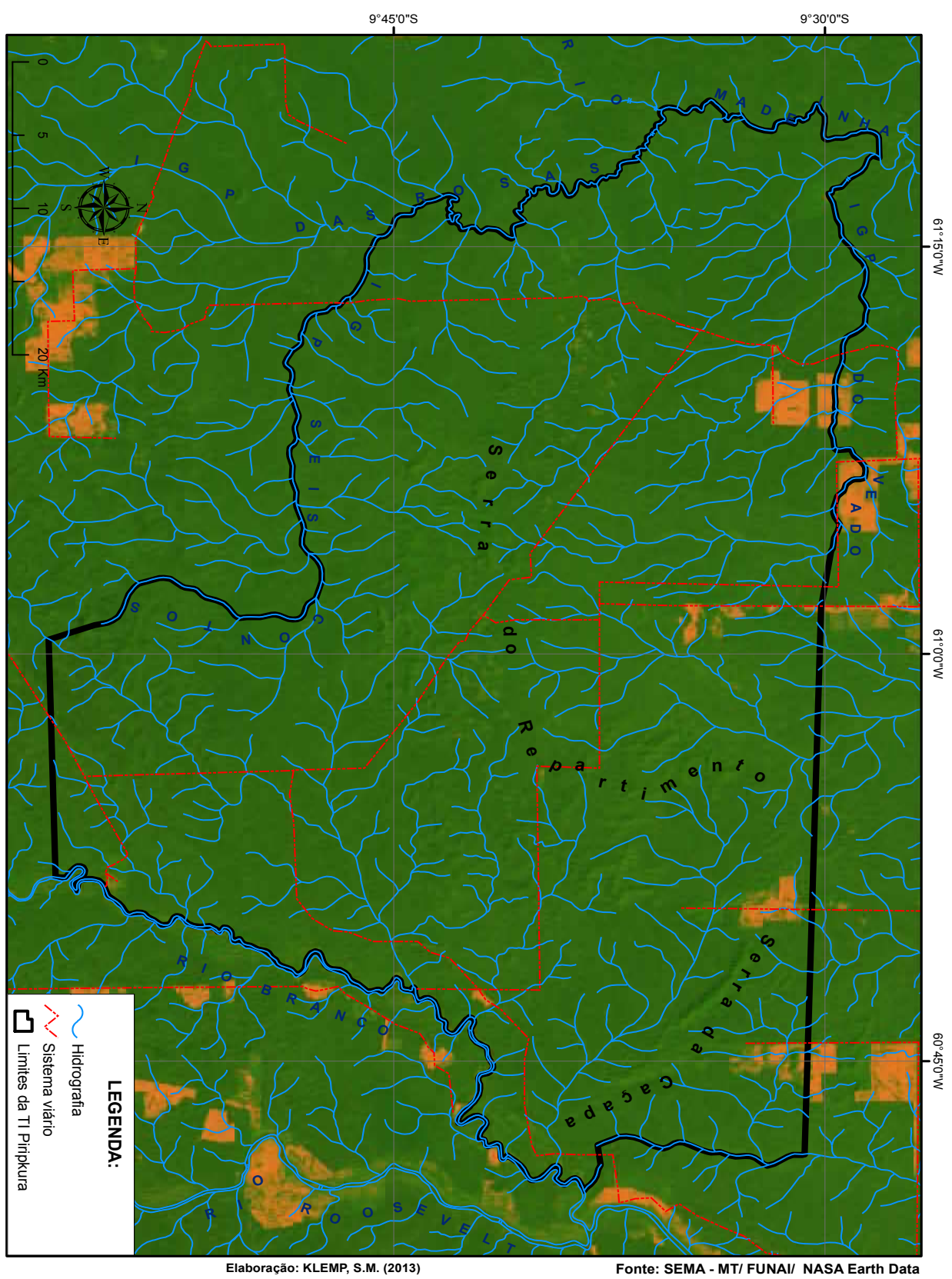

Os impactos observados na TI-PRK e seu entorno imediato correspondem ao resultado da implementação, por não-índios, de atividades de garimpo, extração 
de madeira e agropecuária. Assim, durante o sobrevoo, foi observado nas regiões sudeste, leste e nordeste do território a presença de estradas abandonadas e em uso, carreadores abandonados de madeireiros, desmatamento antigo e recente, pastagens abandonadas e também com presença de gado, cabeceiras de igarapés degradadas, igarapés em situação de assoreamento, e também dois focos de incêndio em áreas de pastagem. Nas regiões noroeste, oeste e sudoeste foram observados os mesmos impactos, entretanto eles aparentam ser menos intensos e concentrados entre os extemos noroeste e norte do limite da TI-PRK e ao longo da denominada "estrada do 180 ", que corta o leste do território no seu sentido Norte-Sul. Estes impactos foram qualificados (datados, georeferenciados e descritos) em 103 registros distintos da presença de não-índios pela FPE-MJ durante suas atividades de fiscalização e monitoramento da TI-PRK realizadas entre 2006 e 2010.

$\mathrm{O}$ relativo bom estado de conservação da TI-PRK permite inferir que ela ainda mantém boa integridade ambiental e, consequentemente, condições adequadas para abrigar a diversidade florística e faunística com ocorrência esperada para a região. Esta integridade permite extrapolar para TI-PRK as informações levantadas por meio da consulta a dados secundários de que os grupos da fauna e da flora apresentam composição diversificada de espécies na região, e que a mesma é categorizada pelo Ministério do Meio Ambiente como de alta prioridade para a conservação (EPE 2011: 22 a 27 e 56 a 91; SDS/AM 2010: 96 a 116; Brasil 1978: 498 a 503). Os estudos demonstram a ocorrência de 97 espécies de peixes, 125 de anfíbios, 127 de répteis, 509 de aves, 113 de mamíferos (EPE 2011: 22 a 27 e 56 a 91). Estas listas contemplam as espécies de peixes, répteis (jacarés, tartarugas e cágados), aves (nambús, jacús, mutuns) e mamíferos (anta, porcos-do-mato, veados, cutias, paca) conhecidas pelos Piripkura, conforme informações levantadas junto a Rita.

No que tange à flora, o inventário botânico realizado na RESEX-Guariba em uma área amostral de dois hectares, permitiu catalogar 177 espécies arbóreas (em 527 indivíduos) nas formações florestais (FOA e FOD) situadas na terra firme, e 129 (em 495 indivíduos) naquelas de ocorrência nas várzeas (SDS/AM 2010: 96 a 116). No inventário realizado em cinco pontos distintos da TI-PRK, o número de espécies por hectare oscilou entre 30 e 54 (entre 55 e 80 indivíduos amostrados) (Brasil 1978: 503). Nestes cinco pontos, as espécies arbóreas mais comuns no extrato superior da floresta foram: abioranarosadinha (Pouteria anomala), abiorana-cutite (Pouteria macrocarpa), abiorana-seca (Pouteria caimito), abiorana-branca (Pouteria guianensis), itaúba (Mezilaurus spp.), mututi (Pterocarpus santalinoides), tauari (Couratari guianensis), acapú (Vouacapoua americana), sucupira (Diplotropis purpurea), cajuaçu (Anacardium giganteum), ucuuba-chorona (Virola surinamensis), angelim-pedra (Hymenolobium spp.), castanheira (Bertollethia excelsa), parapará (Jacaranda copaia), taxi-pitomba (Tachigali chrysophylla), ipê- 
roxo (Handroanthus impetiginosus), jutaí-pororoca (Dialium guianensis), janitá (Brosimum alicastrum), uxirana (Licania octandra), angelim-da-mata (Hymenolobium spp.), visgueiro (Parkia paraensis), taxi-preto (Tachigalia myrmecophilla), cumaru (Coumarouna odorata), freijó (Cordia goeldiana), jutaí-mirim (Hymenaea intermedia), breu-manga (Tetragastris altissima), morácea-chocolate (Pseudolmedia laevis), caucho (Castilla ulei), breu-vermelho (Protium heptaphyllum), breu-preto (Protium opacum), macucu-de-sangue (Licania heteromorpha), sucupira-amarela (Bowdichia nitida), burra-leiteiraa (Sapium marmieri), piquiá-marfim (Aspidosperma album), samaúma (Ceiba pentandra), quaruba-cedro (Vochysia maxima), cupibúba (Goupia glabra), pente-de-macaco (Apeiba echinata), jatobá (Hymenaea courbaril), cedrinho (Erisma uncinatum), peroba (Aspidosperma macrocarpon), mandioqueirarosa (Qualea dinizii), mamorana (Pachira paraensis). As espécies de palmeiras mais comuns foram: babaçu (Attalea dspeciosa), inajá (Atallea maripa), buriti (Mauritia flexuosa), bacaba (Oenocarpus bacaba), patauá (Oenocarpus bataua), tucumã (Astrocaryum aculeatum), açaí (Euterpe precatoria), paxiuba (Iriartea exorrhiza), paxiuba-barriguda (Iriartea deltoidea), murumuru (Astrocaryum murumuru) e mumbaca (Astrocaryum gynacamthum). Dentre os cipós os mais comuns foram: graxama-branca (Cydista aequinoctialis), escada-de-jabuti (Bauhinia splendens), de-fogo (Doliocarpus rolandri), titica (Heteropsis flexuosa), de-sangue (Machaerium quinata), imbé (Philodendron imbe), capa-homem (Davilla rugosa), unha-de-gato (Uncaria tomentosa) e japecanga (Smilax sp.).

\section{Memórias de Rita Piripkura sobre o uso e ocupação da TI-PRK e seu entorno}

Informações levantadas junto a Rita Piripkura permitiram conhecer parte do CET-Piripkura quanto aos lugares utilizados, tipos de recursos e estratégias para obtê-los. Durante sua convivência com seus parentes Piripkura, entre as décadas de 60 e 70, ela ouviu relatos de sua avó, tio, pai e mãe em que seus antepassados (pais de sua avó) frequentavam os igarapés das Rosas, Seis Contos e dos Índios, situados além do limite sudoeste da TI-PRK, e o igarapé das Panelas, do qual somente as cabeceiras estão inseridas no limite nordeste da TI-PRK. Estas microbacias somam-se àquelas contidas no território atualmente interditado, para as quais Rita relata uso e ocupação por ela e sua parentela durante o período em que viveu efetivamente na TI-PRK. Nessa época, sobreviviam essencialmente da caça, pesca, coleta de frutos e mel, pois Rita recorda que o plantio de pequenas áreas de roças era feito até a fase em que era criança. Entretanto, ela mencionou que sua avó narrava que seus avós maternos e paternos faziam roçados maiores, visto que outrora somavam maior número de pessoas. 
Quanto ao uso do território no referente ao igarapé repartimento Urukutýwuhúa, Rita mencionou a presença de malocas, por sua vez corroborada por relatos da expedição realizada em 1986 pela equipe da OPAN. E por ter composto a equipe e haver habitado o local, Rita soube discernir por quem cada uma das duas malocas foi habitada. Para o igarapé Seis Contos jakaréa, relatou que os progenitores de sua avó plantavam roça nessa região e que nele também realizavam caça e pesca. Estas duas últimas atividades também eram realizadas no igarapé da Paca Iãpetéga, Garça do Índio Iakahukába, Garça do Branco Yrytýbuhúa e Duelo Tatapãja. Para as cabeceiras dos igarapés das Panelas e do Veado informou que parte de sua parentela coletava a taquara kamajú utilizada para confeccionar a haste principal da flecha.

Em relação à atividade de caça, Rita relatou que havia diferenças entre os dois subgrupos quanto às estratégias, pois somente um deles ainda dominava a técnica de confecção de arco e flecha, lhes permitindo abater aves (nambús nambúa, mutum mutúa e jacú jakúa) e mamíferos de médio e grande porte (anta tapi'íra, queixada tajaúa e cateto taitúa). Os outros empreendiam caça praticamente restrita à paca e cutia, por sua vez abatidas em suas tocas após os indígenas cavarem buraco onde eram encurraladas. As informações de Rita permitem compreender que outrora a caça compreendia maior diversidade de espécies e não era restrita a determinados grupos, pois ela não fez referências a outros tabus alimentares, excetuando os relacionados a resguardo por menstruação e amamentação. Rita soube dizer na língua Piripkura os nomes para arco ywýrapára, flecha 'y'ýwa e recursos utilizados em sua confecção. No que tange à pesca, ela mencionou haver duas estratégias, uma utilizando timbó e outra tocha-de-fogo. Na primeira, usa-se uma espécie vegetal, colocada na água para asfixiar os peixes e, na segunda, a tocha, empregada para iluminar a margem do igarapé, permitindo, desse modo, ver o peixe e golpeá-lo com um pedaço de pau; as espécies de peixe citadas foram cará akará, piau pijawá, traíra tare 'ýra, jeju tijú, bodó ijĩ'á, arraia txawe 'wýra e camboatá ambuatá. A coleta de mel é feita, segundo Rita, em qualquer lugar e momento que se encontre uma colmeia; as espécies de abelha citadas foram juparáju'ía 'jandaíra', heira po'á 'espécie de abelha', ywahúa 'abelha pai', heiretéa 'uruçu', borouhúa 'espécie de abelha pequena', tata 'íra 'abelha de fogo', heiryy'ria 'espécie de abelha que fica no cipó (no chão), akupytanuhúa 'abelha grande que produz mel no mês de janeiro', tapemánga 'espécie de abelha'.

As incursões pelos igarapés da Paca Iãpetéga, Garça do Índio Iakahukába, Garça do Branco Yrytýbuhúa realizadas com Rita e as entrevista que fizemos junto a ela permitiram levantar conhecimento sobre espécies vegetais e seus usos (Tabela 1). As 68 espécies identificadas estão representadas por 60 árvores, seis palmeiras e dois cipós; Rita não foi interrogada quanto ao uso de outros grupos vegetais. Dentre as espécies, ela relatou que 39 são utilizadas como alimento (frutos), três como fonte de embira para confeccionar rede, duas são 
úteis na construção de tapiris, três para a pesca, três para fazer arco e flecha, e onze são utilizadas como alimento pela fauna. Este conjunto de usos sugere que parte do atual conhecimento de Rita sobre a diversidade florística, após ter vivido fora do seu território por cerca de 20 anos, inclui aquelas espécies essenciais para sua sobrevivência e de sua parentela.

\section{Tabela 1. Espécies vegetais e seus usos conforme informações colhidas junto à índia Rita Piripkura.}

\begin{tabular}{|c|c|c|c|}
\hline Nome & Nome Piripkura & Nome científico & Uso \\
\hline Abiu & $a j u$ 'ybá & Pouteria sp.1; Pouteria & Fruto \\
\hline Abiu & owetíngapauhúa & Pouteria torta & Fruto \\
\hline Abiu-cotite & aju'ybá ipotýra & Pouteria macrophylla & Fruto \\
\hline Abiurana & aju'ybárána & Pouteria caimito & Fruto \\
\hline Angelim & yway'áka & Dinizia excelsa & Conhece \\
\hline Araça & Bureápikía & Eugenia sp.1 & Fruto \\
\hline Araça & pubururéa piránga & Eugenia sp.2 & Fruto \\
\hline $\begin{array}{l}\text { Araça-de- } \\
\text { anta }\end{array}$ & hemu'y'ýwa & Berllucia grossularioides & Fauna \\
\hline Arariúba & okýta'a i'a & Minquartia guianensis & Conhece \\
\hline Babaçu & Inatáuhúa & Orbignya phalerata & Fruto; Tapiri \\
\hline Bacaba & panakúpupéja & Oenocarpus bacaba & Fruto \\
\hline Breu & yhýka/jutahýka & Protium heptaphyllum & Fruto; Resina \\
\hline Buriti & majīkujýwa & Mauritia flexuosa & $\begin{array}{c}\text { Fruto; } \\
\text { Artesanato }\end{array}$ \\
\hline Cacau & $\frac{\text { jumitauhúa (tem na }}{\text { terra) }}$ & Theobroma sp.1 & Fruto \\
\hline Cacau & tarapúa & Theobroma sp.2 & Fruto \\
\hline Cacauí & kupu'ía & Theobroma speciosum & Fruto \\
\hline Cachimbeira & txitykywýwa & Cariniana rubra & Fruto \\
\hline Cajá & akajáb & Spondias mobim & Fruto \\
\hline Cajuí & akajuhúa & Anacardium giganteum & Fruto \\
\hline Cambuí & aerembíwe 'ýma & Psidium sartoriano & Fauna \\
\hline Castanha & $j \underline{a}$ & Bertholetia excelsa & Fruto \\
\hline Cipó-timbó & timó/moapáwuhúa & Não indentificado & Pesca \\
\hline Cipó-titica & ipóa & Heteropsis flexuosa & Utensílio \\
\hline Copaíba & txyrykytíwopéa & Copaifera langsdorffii & Fauna \\
\hline Copiúva & ejoybába píra & Tapirira guianensis & Fruto \\
\hline Cupuaçu & jumitahýma & Theobroma grandiflorum & Fruto \\
\hline Embaúba & makawa 'ýwuhúa & Cecropia sp. 1 & $\begin{array}{l}\text { Corda para } \\
\text { arco; Rede }\end{array}$ \\
\hline Embaúba & amba'ýwa (pequena) & Cecropia sp. 2 & $\begin{array}{l}\text { Corda para } \\
\text { arco; Rede }\end{array}$ \\
\hline Envira-preta & Sem nome & Bocageopsis multiflora & Conhece \\
\hline Faveiro & inamburúywopéa & Gleditschia sp. & Conhece \\
\hline Guanadi & hea'netangiwauhúa & Calophyllum brasiliensis & Fruto \\
\hline
\end{tabular}




\begin{tabular}{|c|c|c|c|}
\hline $\begin{array}{l}\text { Nome } \\
\text { comum }\end{array}$ & Nome Piripkura & Nome científico & Uso \\
\hline Imbaubarana & amba'ýwarána & Pouroma guianensis & Fruto \\
\hline Inajá & inata'ýwa & Maximiliana maripa & Fruto \\
\hline Ingá & ykangaká & Inga edulis & Fruto \\
\hline Ingá & ingáperemu’húa & Inga sessilis & Fruto \\
\hline Ingá-feijão & paji'ýja & Inga cilindrica & Fruto \\
\hline Ingá-mirim & ynga'ía & Inga laurina & Fruto \\
\hline Ingarana & ywyruajirána & $\begin{array}{l}\text { Dimorphandra } \\
\text { macrostachya }\end{array}$ & Conhece \\
\hline Ipê-amarelo & Sem nome & Handroanthus ochaceus & $\begin{array}{l}\text { Arco; Ponta de } \\
\text { flecha }\end{array}$ \\
\hline Itaúba & kujapi'ýwa & Mezilaurus itauba & Fauna \\
\hline Jatobá & juta'ýwa & Hymenaea sp. & Fruto \\
\hline Jatobá-mirim & piraiwýwa & Guibourtia sp. & Conhece \\
\hline Jenipapo & jandypáwa & Genipa americana & Fruto \\
\hline $\begin{array}{l}\text { Jutaí- } \\
\text { pororoca }\end{array}$ & juta'ía & Dialium guianense & Fruto \\
\hline Maçaranduba & $\frac{\text { aweting ywal }}{\text { howetxiby'ría }}$ & Manilkara huberi & Fruto \\
\hline Matamatá & ywotyrýwa & Lecythes chatacea & Fauna \\
\hline Muirapimina & ywarapi'yja & Brosimum guianense & Fruto \\
\hline $\begin{array}{l}\text { Murici-da- } \\
\text { capoeira }\end{array}$ & manikujúwa & Byrsonima sp. & Fruto \\
\hline $\begin{array}{l}\text { Paineira- } \\
\text { barriguda }\end{array}$ & $\underline{k w a r a ́ m a n d y j u ́ w a}$ & Ceiba sp. & Conhece \\
\hline Pajurá & apirahya & Couepia bracteosa & Fruto \\
\hline Patauá & pindóab & Oenocarpus bataua & Fruto \\
\hline Pau-breu & kwapaýwa'uhúa & Symphonia globulifera & Fauna \\
\hline $\begin{array}{l}\text { Pau-de- } \\
\text { embira }\end{array}$ & embýra'ýwa & Xylopia frutescens & Conhece \\
\hline Pequiarana & makwawa ywuhúa & Caryocar microcarpum & Fauna \\
\hline Piquiá & peki'á & Caryocar villosum & Fruto \\
\hline $\begin{array}{l}\text { Pupunha- } \\
\text { brava }\end{array}$ & ipykáwa & Bactris sp. & Arco \\
\hline Pupunharana & $\underline{\text { akajárána }}$ & Duckeodendron cestroides & Fauna \\
\hline Rebenta-laço & Sem nome & Banara arguta & Fauna \\
\hline Sorva & $\underline{\text { txúwa }}$ & Couma utilis & Fruto \\
\hline Tachi-branco & Sem nome & Sclerolobium paniculatum & Conhece \\
\hline Tamboril & timbo'ýwopéa & Enterolobium timbouva & Fauna; Pesca \\
\hline Tarumã & kirupina'é & Vitex cimosa & Fruto \\
\hline Tatajuba & ywaputuka'ýwa & Bagassa guianensis & Fauna \\
\hline Tauari & jityky & Não indentificado & $\begin{array}{l}\text { Embira para } \\
\text { rede }\end{array}$ \\
\hline Umari & Sem nome & Paraqueiba sericia & Fruto \\
\hline Urucum & $\underline{\text { Urukú }}$ & Bixa orellana & Pintura \\
\hline Uxi & muntu'úba & Endopleura uchi & Fruto \\
\hline Uxirana & witirána & Sacoglottis guianensis & Fruto \\
\hline
\end{tabular}




\section{Uso e ocupação da TI-PRK pelos Piripkura}

\section{Caracterização geral dos vestígios}

Entre os anos de 1985 e 2012 foram registrados e catalogados vestígios que comprovam o uso e ocupação da TI-PRK pelos índios Piripkura (Tabela 2). A análise conjunta dos mesmos permitiu qualificá-los em 44 itens relacionados a recursos da fauna e da flora utilizados pelos indígenas ou em estratégias para acessá-los. Na lista, merecem destaque, em um primeiro momento, itens encontrados nos seus abrigos, pertencentes à sua cultura material, cabo de machado, cobertor, facão, machado, panela de alumínio e roupas. Dentre estes, há entendimento que somente o facão e o machado são rotineiramente utilizados pelos indígenas, pois sempre estão portando estes instrumentos quando a equipe da FPE-MJ tem oportunidade de vê-los na mata. A partir destes encontros a equipe também relata que os dois indígenas sempre estão nus, que o preparo de alimentos é majoritariamente feito com o moquém e que o cobertor foi encontrado somente uma vez e estava sendo utilizado para acondicionar peixe moqueado.

Entre os vestígios, foram registrados 107 abrigos, por sua vez qualificados como malocas, tapiris e rabos de jacu. Esses abrigos se diferenciam basicamente quanto à forma, mas todos têm sua estrutura de sustentação construída empregando-se uma associação variável de troncos de árvores vivas com pedaços de paus roliços atados por amarrações, típicas dos Piripkura, feitas com cipós e embiras, e teto ou cobertura feita principalmente de folhas de babaçu. As malocas, encontradas somente entre os anos de 1985 e 1986, apresentam forma retangular, não têm paredes e o teto é triangular de duas águas, quando visto em corte transversal. Os tapiris não têm paredes laterais, são de forma retangular e teto que pode se apresentar plano pela pouca quantidade de folhas de babaçu, principalmente na estação seca, ou se apresentar com duas águas, devido ao maior número de folhas colocadas em seu eixo central. O rabo de jacú tem estrutura similar às traves de um gol e sua cobertura é feita apoiando-se as folhas das palmeiras entre a barra horizontal e o chão, resultando em um abrigo de "uma água" com inclinação aproximada de 45 graus. Há entendimento pela equipe da FPE-MJ que o rabo de jacú se constitui em abrigo passageiro, feito para pernoitar ou se proteger de uma chuva; nele dificilmente são encontrados vestígios de cultura material e alimentar, como é registrado na maloca e no tapiri. Assim, entende-se que estes últimos compreendem importantes pontos de referência geográfica para os indígenas quando estão ocupando determinada área de seu território, ou seja, são os lugares para dormir e descansar (presença de rede e de esteiras), para levar os alimentos (presença de cestarias), preparálos (presença de moquém, pilão) e consumi-los (presença de restos alimentares como ossos, cascos de jabuti e sementes). 
Os dados contidos na tabela 2 mostram que os Piripkura sobrevivem majoritariamente da coleta de pelo menos três espécies de frutos (babaçu, castanha e cacau), da coleta do caratinga, da pesca de pequenos peixes em igarapés e da caça de jacaré jakaré (Caiman spp., Paleosulchus spp.), de paca, karuwáruhúa (Agouti paca), de jabuti, txautxía (Geochelone spp.) e de porcodo-mato, tajahúa (Tayassu pecari e Pecari tajacu). A caça é realizada por meio de busca ativa, iniciada pelo encontro de um vestígio do animal (rastro ou toca), culminado no abate do mesmo no local onde este se encontra; a paca é abatida na toca, daí a presença de "buraco no chão", e o jacaré é fisgado/abatido com varas compridas. Este utensílio é empregado ainda para fisgar o peixe bodó (ijĩ 'á) na época da seca quando está dentro de buracos feitos pelas espécies nos barrancos dos igarapés. A pesca também é feita utilizando timbó, extraído da casca de árvore e do cipó-timbó, que é "batido" nos igarapés em locais onde há formação de poças na estação seca ou onde elas são criadas artificialmente pelos indígenas fazendo-se cerco com folhas de babaçu; daí a presença do vestígio "barragem de igarapé". Em uma ocasião os dois Piripkura relataram ter "roubado" de duas onças, em momentos distintos, uma anta e um porco-domato recém abatidos pelos felinos e os consumiram (Jair Candor; comunicação pessoal).

\section{Tabela 2. Caracterização dos vestígios encontrados na TI-PRK entre os anos de 1985 e 2013.}

\begin{tabular}{|c|c|}
\hline Vestígio & Descrição \\
\hline Árvore derrubada & $\begin{array}{c}\text { Diferentes espécies de árvores derrubadas a machado pelos } \\
\text { indígenas para coletar frutos e mel. }\end{array}$ \\
\hline Árvore queimada & $\begin{array}{c}\text { Diferentes espécies de árvores queimadas pelos indígenas } \\
\text { para coletar frutos e mel. }\end{array}$ \\
\hline Babaçu & $\begin{array}{l}\text { Espécie de palmeira (Orbignya phalerata) cujos frutos } \\
\text { (exocarpo) são consumidos pelos indígenas e cujas folhas } \\
\text { são utilizadas para confeccionar a cobertura de tapiris e } \\
\text { cestarias. }\end{array}$ \\
\hline Barragem de pesca & $\begin{array}{c}\text { Barramento de trechos de igarapés com folhas de palmeiras } \\
\text { para realizar pesca com timbó na estação seca. }\end{array}$ \\
\hline Buraco no chão & $\begin{array}{l}\text { Vestígio gerado como resultado da caça de paca (Agouti } \\
\text { paca) e de jacaré (Caimam spp. ou Paleosuchus spp.) pelos } \\
\text { Piripkura. }\end{array}$ \\
\hline Cabo de machado & $\begin{array}{l}\text { Pedaço de madeira moldado por não-índios para encabar } \\
\text { manchado de ferro. }\end{array}$ \\
\hline Caco de panela & $\begin{array}{c}\text { Pedaços de panelas de barro indicativo da presença de sítio } \\
\text { arqueológico indígena. }\end{array}$ \\
\hline
\end{tabular}




\begin{tabular}{|c|c|}
\hline Vestígio & Descrição \\
\hline Caratinga & $\begin{array}{l}\text { Espécie de cará nativo (espécie não identificada) utilizado } \\
\text { como alimento pelos Piripkura.. }\end{array}$ \\
\hline Carne & $\begin{array}{l}\text { Carne de algum tipo de animal encontrada nos tapiris dos } \\
\text { Piripkura }\end{array}$ \\
\hline Castanha & $\begin{array}{l}\text { Frutos da castanheira (B. excelsa). São consumidos in } \\
\text { natura ou moqueados. }\end{array}$ \\
\hline Castanhal & Agrupamento de indivíduos de castanheira (B. excelsa). \\
\hline Cestaria & $\begin{array}{l}\text { Utensílios confeccionados pelos Piripkura trançando-se } \\
\text { folíolos da folha da palmeira babaçu }(O \text {. phalerata }) \text {. }\end{array}$ \\
\hline Cipó-titica & $\begin{array}{l}\text { Tipo de cipó utilizado comumente para amarrar os paus } \\
\text { que sustentam os tapiris. Também na confecção de "jirau" } \\
\text { e "escadas" que facilitam acesso a recursos de difícil } \\
\text { acesso. }\end{array}$ \\
\hline Cobertor & $\begin{array}{l}\text { O mesmo cobertor dos não-índios. Utilizado pelos } \\
\text { Piripkura para acondicionar peixe moqueado. }\end{array}$ \\
\hline Embira & $\begin{array}{l}\text { Conjunto de casca e entrecasca de distintas espécies de } \\
\text { árvores. É utilizada como "corda" para diversos fins, entre } \\
\text { eles a confecção de rede para dormir. }\end{array}$ \\
\hline Facão & $\begin{array}{c}\text { O mesmo facão dos não-índios. Utilizado para se realizar a } \\
\text { extração dos recursos naturais diversos. }\end{array}$ \\
\hline Fogueira & Local onde se faz fogo para usos diversos. \\
\hline Jabuti & $\begin{array}{l}\text { Espécie animal (Geochelone spp.) utilizado como } \\
\text { alimento. }\end{array}$ \\
\hline Jacaré & $\begin{array}{c}\text { Espécie animal (Caimam spp. ou Paleosuchus spp.) } \\
\text { utilizado como alimento. }\end{array}$ \\
\hline Jirau & $\begin{array}{c}\text { Armação feita com pedaços de pau, cipós e embiras. } \\
\text { Apresentam forma diversas, adaptadas para facilitar o } \\
\text { acesso aos recursos naturais. }\end{array}$ \\
\hline Mel & $\begin{array}{c}\text { Produto de origem animal de sabor adocicado e elaborado } \\
\text { por distintas espécies de abelhas. }\end{array}$ \\
\hline Mochila & $\begin{array}{l}\text { Utensílio de não-índio para carregar roupas. Provavelmente } \\
\text { utilizada pelos Piripkura para carregar alimentos (castanha, } \\
\text { peixe e frutos diversos). }\end{array}$ \\
\hline Moquém & $\begin{array}{c}\text { Armação de madeira em forma triangular sobre a qual } \\
\text { se colocam paus roliços e abaixo destes faz-se fogo. } \mathrm{O} \\
\text { moquém é utilizado para assar alimentos como caças, } \\
\text { peixes e castanha. }\end{array}$ \\
\hline Ossos & $\begin{array}{l}\text { Partes do esqueleto de algum animal abatido e/ou } \\
\text { consumido pelos Piripkura. }\end{array}$ \\
\hline Paca & Espécie animal (A. paca) utilizado como alimento. \\
\hline
\end{tabular}




\begin{tabular}{|c|c|}
\hline Vestígio & Descrição \\
\hline Palhal & Agrupamento de indivíduos de babaçu (O. phalerata). \\
\hline Panela de alumínio & $\begin{array}{l}\text { O mesmo utensílio dos não-índios. Utilizada para preparar } \\
\text { alimentos. }\end{array}$ \\
\hline Pedaços de pau & $\begin{array}{c}\text { Pedaços de pau cortados, provavelmente utilizado como } \\
\text { lenha. }\end{array}$ \\
\hline Pegada & $\begin{array}{l}\text { Marcas dos pés dos Piripkura no solo deixadas em } \\
\text { conseqüência de seu deslocamento pelo território. }\end{array}$ \\
\hline Peixe & $\begin{array}{c}\text { Animais vertebrados, de hábitos aquáticos e pertencentes } \\
\text { ao grupo dos Osteíctes. Utilizados como alimento, } \\
\text { principalmente na estação seca. }\end{array}$ \\
\hline Picada & $\begin{array}{l}\text { Trilhas feitas pelos Piripkuras para facilitar seu } \\
\text { deslocamento pela mata. Podem ser bem ou mal } \\
\text { delimitadas, provavelmente como consequência de } \\
\text { sentirem-se mais ou menos seguros quanto à presença de } \\
\text { não-índios em determinada região de seu território. }\end{array}$ \\
\hline Pilão & $\begin{array}{l}\text { Pedaço de tronco de árvore com buraco afunilado. Serve } \\
\text { como utensílio para preparar alimentos como farinha de } \\
\text { peixe e de babaçu. }\end{array}$ \\
\hline Ponto de dormida & Local utilizado pelos indígenas para repousar ou pernoitar. \\
\hline Porco-do-mato & $\begin{array}{c}\text { Espécie animal (Tayassu pecari e Pecari tajacu) utilizado } \\
\text { como alimento. }\end{array}$ \\
\hline Queimada & $\begin{array}{l}\text { Local onde os Piripkura ateiam fogo para facilitar a coleta } \\
\text { do cara caratinga. }\end{array}$ \\
\hline Rede & Utensílio para dormir confeccionado de embira. \\
\hline Roupa & $\begin{array}{l}\text { Vestimentas de não-índios. Encontrada nos tapiris dos } \\
\text { Piripkura, mas não utilizada por eles como vestimenta. }\end{array}$ \\
\hline Timbó & Espécie vegetal útil para realizar a "pesca com timbó". \\
\hline Tocha & $\begin{array}{l}\text { Utensílio para carregar e manter fogo, feito da bráctea de } \\
\text { palmeira. }\end{array}$ \\
\hline Uruá & $\begin{array}{l}\text { Tipo de cesto confeccionado trancando-se os folíolos da } \\
\text { folha de babaçu (O. phalerata). }\end{array}$ \\
\hline Vara & $\begin{array}{c}\text { Pedaço de madeira fina e longa empregada para coletar } \\
\text { frutos. }\end{array}$ \\
\hline
\end{tabular}

A análise conjunta dos vestígios deixados pelos indígenas demonstra que os frutos ou são coletados do chão, ou apanhados por meio de vara, ou derrubando a árvore, atividade que pode ou não ser feita com a construção de jirau. Neste caso, ele terá a forma e altura que os indígenas julgarem adequado para cortar o tronco com machado. O jirau também pode ser empregado na coleta do mel, mas neste caso toma a forma de uma escada para permitir alcançar a colmeia de 
abelhas. A coleta de mel e de frutos ainda pode ser realizada ateando-se fogo na árvore. $\mathrm{O}$ transporte destes itens do local de coleta para os abrigos ou qualquer outro local é feito utilizando as cestarias, majoritariamente confeccionadas com folhas de babaçu. A evidência da perambulação dos Piripkura pelo território é frequentemente indicada pelas picadas; elas podem se mostrar pouco ou muito evidentes a depender, dentre outros fatores, da presença de não-índios, da disponibilidade de recursos (castanhal e palhal) e da necessidade de acessar abrigos e pontos de travessia entre microbacias de igarapés (Jair Candor; comunicação pessoal).

\section{Uso e ocupação da TI-PRK e de seus recursos}

A análise dos vestígios catalogados pela equipe da FPE-MJ quanto à época de uso e localização geográfica permitiu discorrer sobre a dinâmica de uso da TI-PRK e dos recursos da fauna e flora utilizados pelos Piripkura. Entre $1985^{24}$ e 2013 eles utilizaram pelo menos ${ }^{25}$ cinco microbacias distintas (Figura 5). Assim, especificamente entre 2005 e 2012, o número de registros de abrigos por estação climática anual mostra tendência de uso do igarapé da Paca em 2005; ocupação do Garça-do-branco, Duelo, Garça-do-índio e Repartimento em 2006 e 2007; ocupação majoritária do Duelo em 2008 e 2009; retomada de uso dos igarapés Garça-do-índio e do Garça-do-branco em 2010 e 2011 e do Repartimento em 2012.

\footnotetext{
${ }^{24}$ Entre 1988 e 1990 a FPE-MJ encontrou vestígios da presença de Tikum e Monde’í nos igarapés do Índio, Repartimento, da Paca, Garça-do-índio, Garça-do-branco e Duelo. Também encontraram vestígios antigos, com idade estimada entre 5 e 10 anos e provavelmente de outros Piripkura, nos igarapés das Panelas, do Veado, da Serra e das Rosas.

${ }^{25}$ A expressão "pelo menos" está colocada porque esta figura aborda somente os abrigos, aqui considerados como sendo os pontos de referência geográfica dos indígenas, e pelo fato de suas localizações terem sido agrupadas pelo leito principal dos igarapés, ou seja, seus afluentes não estão sendo considerados como igarapés distintos, embora isto seja plausível na perspectiva dos indígenas.
} 
Figura. 5. Distribuição espacial dos tapiris encontrados nas expedições realizadas entre os anos de 2007 e 2013 nos limites internos da TI-PRK.

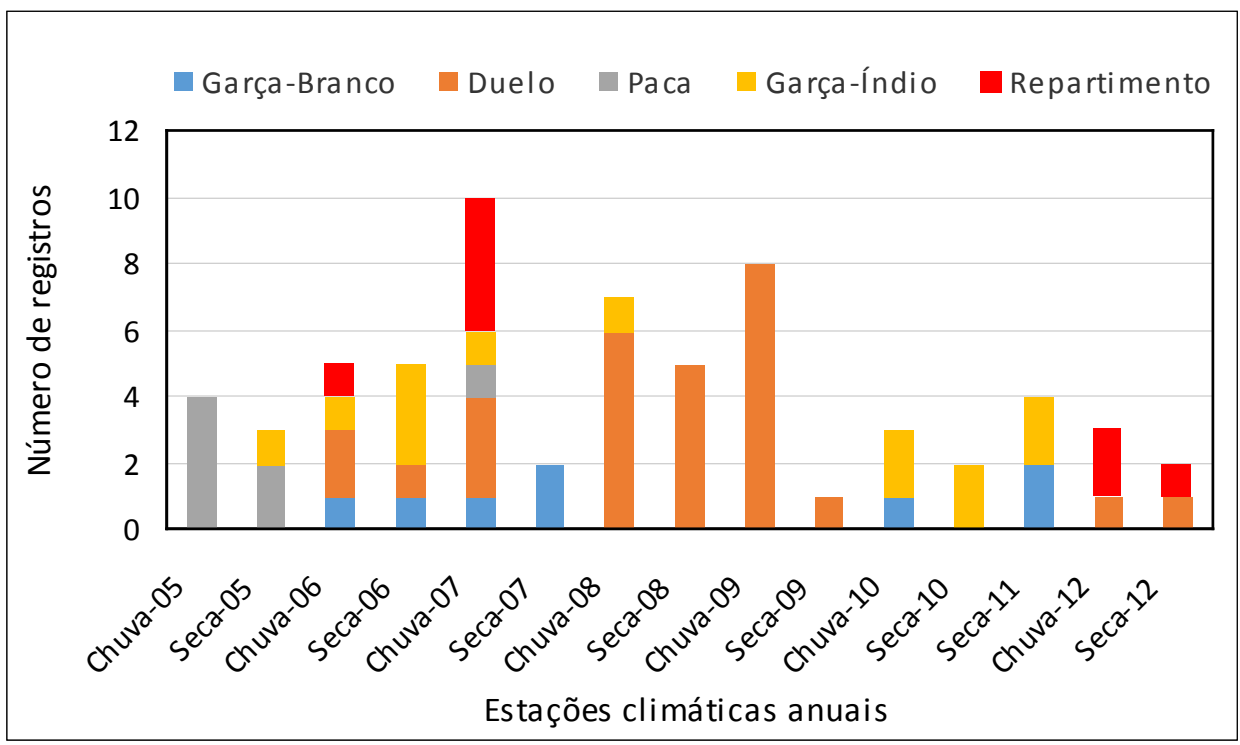

O total de vestígios qualificados por microbracias sugere semelhança entre as mesmas em relação ao uso de seus recursos pelos Piripkura e também quanto às estratégias realizadas para acessá-las (Figura 6). Assim, dos seis igarapés, em cinco foi constatada a prática da coleta de mel, em quatro a de castanha e em três o consumo de jacaré, de peixe e de paca; este último item corresponde à soma dos vestígios "paca" e "buraco no chão", por sua vez qualificado pela FPE-MJ como resultado da caça de paca (Agouti paca). No que tange ao modo de acessar e preparar os alimentos, foram encontradas "picadas", "árvore derrubada" e moquém em cinco igarapés; "árvore queimada", "queimada", "vara" e pesca com timbó ("timbó" + "barragem igarapé") em três igarapés. Há ainda semelhança quanto ao uso de utensílios, pois "cestaria", "rede" e "tocha" foram registrados em pelo menos três dos seis igarapés. 
Figura 6. Registros de vestígios por igarapé na TI-PRK.

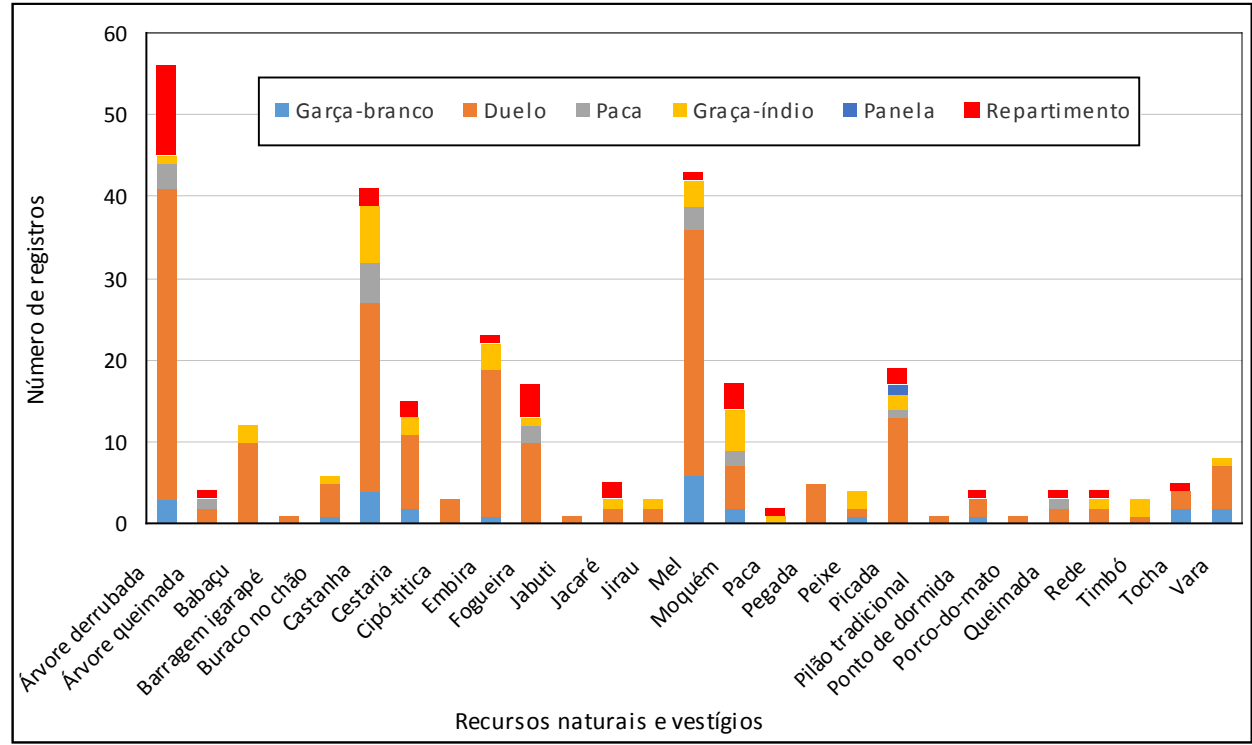

A análise dos registros de vestígios por estação climática anual revela tendências quanto ao uso dos recursos naturais e das estratégias de sobrevivência dos Piripkura (Figura 7). A castanha, o mel e o babaçu figuram como os recursos utilizados com maior frequência, pois ambos são consumidos nas estações seca e chuvosa e vêm sendo catalogados pela FPE-MJ desde 2003 (castanha), 2005 (mel) e 2006 (babaçu), embora também conste nos relatórios de 1988 e 1989. Em relação a tais recursos, cabe destacar o contínuo registro de árvore derrubada, uma das estratégias dos indígenas para acessá-los. A baixa frequência de jabuti, jacaré, paca, peixe e porco-do-mato relativo ao número de tapiris (local onde normalmente são encontrados) e ao tempo de atuação da FPEMJ em campo, embora confirme o uso de caça em diferentes anos e estações, provavelmente não está refletindo o real consumo destes itens. A "ausência" de vestígios de caça e pesca pode estar ocorrendo pela ação dos indígenas, de predadores e do tempo, ou seja, ser consequência do descarte, predação ou degradação das partes não consumidas. Os vestígios relacionados aos utensílios e modo de vida propriamente dito, também mostram semelhança entre as estações, pois fogueira, moquém, cestaria, rede para dormir e tocha fazem parte do cotidiano dos indígenas em qualquer época. A baixa frequência destes itens é consequência de sua degradação pelo tempo, visto serem confeccionados de matéria vegetal. A alta incidência de picadas no ano de 2008 pode estar relacionada à necessidade dos indígenas monitorarem a região (igarapé Duelo) devido à intensa ocupação das microbacias do entorno pelos não-índios para retirada de madeira entre 2008 e 2009. 
Figura 7. Registros do uso e ocupação da TI-PRK por estação climática e ano. ${ }^{26}$

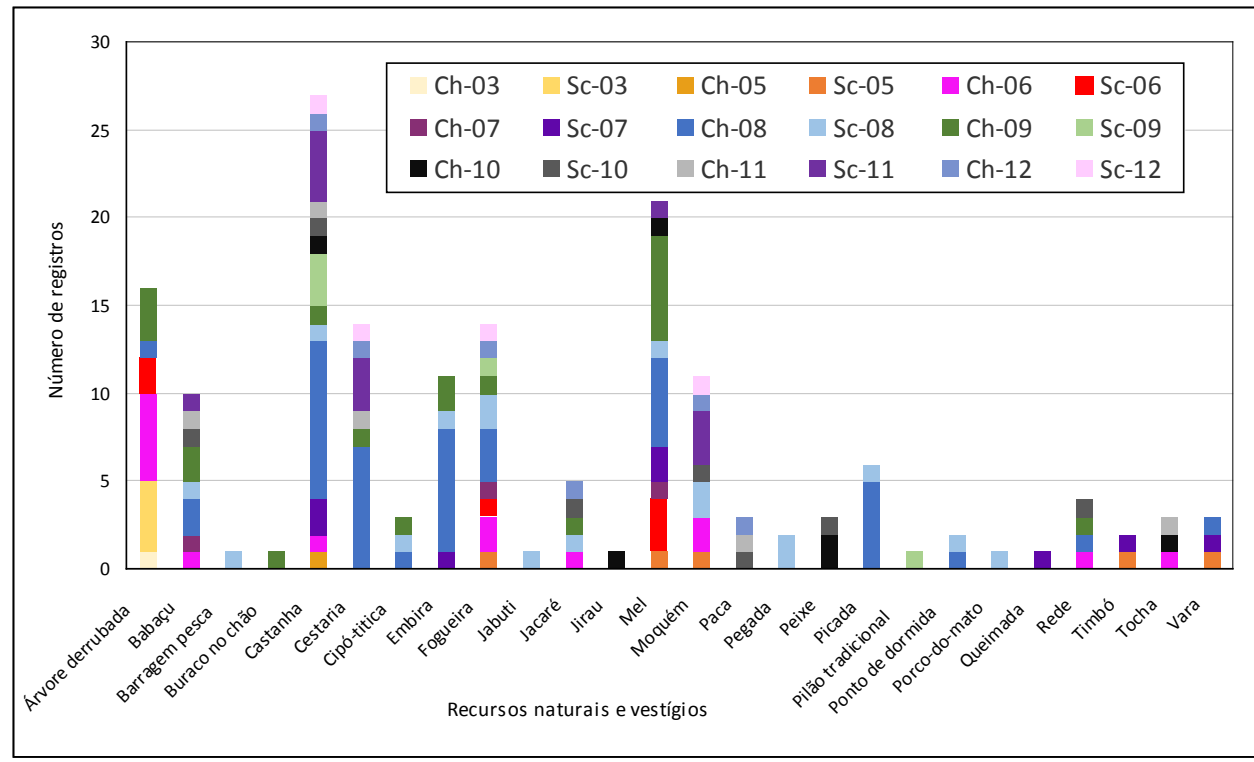

Os dados relativos ao uso do espaço, dos recursos e das estratégias para obtê-los, quando considerados à luz da dinâmica de funcionamento do ecossistema e também da experiência de Jair Candor permite descrever o modo de uso e ocupação da TI-PRK pelos Piripkura. A compreensão é de que no período das chuvas, de outubro a abril, os indígenas tendem a utilizar com maior frequência as cabeceiras dos igarapés, onde se alimentam basicamente de castanha, mel, jacaré, paca, da pesca e, muito provavelmente, de frutos in natura. Com a aproximação da estação seca, de maio a setembro, tendem a descer para a foz dos igarapés em direção àqueles locais que permanecem com água. Nesta fase continuam se alimentando de castanha, mel, jacaré e paca, mas aumentam o consumo de peixes, por sua vez pescados nas poças formadas nos igarapés intermitentes. Com a chegada da estação chuvosa fazem o caminho inverso, ou seja, continuam suas atividades de caça, pesca e coleta rumo às cabeceiras dos igarapés.

\section{Adaptação do CET-Pirikura ao cenário de continuidade do atual modelo de expansão econômica no noroeste de Mato Grosso}

A análise conjunta das informações obtidas no presente trabalho evidencia que o conhecimento e prática do CET-Piripkura esta calcado no manejo adaptativo do uso da biodiversidade presente na heterogeneidade espacial da TI-PRK. Esta

${ }^{26}$ Nota: Ch: chuva; Sc: seca. 
relação coeovolutiva dos Piripkura com os recursos da fauna, da flora e também com o meio físico (clima, solo, relevo e hidrografia) compõe práticas de manejo e mecanismos sociais comuns ao CET de outras comunidades indígenas (Berkes, Colding and Folke 2000). Dentre estas práticas, cabe destacar o uso dos recursos nas escalas da bacia hidrográfica e da heterogeneidade de habitats (manchas de recursos), a capacidade de responder a determinados distúrbios gerados pelos impactos ambientais dos não-índios e o uso múltiplo e rotacional de espécies (realizado pelos antepassados de Rita). Ainda no que diz respeito ao manejo dos recursos naturais, o esperado é que o CET-Piripkura também contemple ou contemplasse o monitoramento da abundância de recursos e a proteção a algum de seus ambientes e de suas espécies, pois seu território tradicional ainda se encontra em bom estado de conservação ambiental. No campo dos mecanismos sociais, os resultados obtidos não permitem discorrer sobre a geração, o acúmulo e a transmissão do CET-Piripkura.

Considerando os impactos negativos gerados ao ambiente pelas atividades dos não-índios na macrorregião onde se insere a TI-PRK, por sua vez materializado pela presença de uma paisagem fragmentada, é possível argumentar que o modelo de expansão econômica em desenvolvimento tem alterado drasticamente o CET-Piripkura no sentido de enfraquecê-lo como estratégia de sobrevivência para os indígenas. Este entendimento se baseia na comparação dos resultados quanto ao uso e ocupação da TI-PRK pelos dois Piripkura obtidas entre 1985 e 2013 , tendo por base os relatos de Rita. Esta comparação indica, em um primeiro momento, que as informações de Rita constituem uma parcela remanescente das estratégias de sobrevivência deste povo, pois durante o tempo em que habitou seu território tradicional já não se plantavam roçados - prática outrora realizada pelos progenitores de sua avó - e o uso de utensílios de caça (arco e flecha) já estava restrito a poucas pessoas, embora fosse de uso comum ao grupo em outro momento. A continuidade da perda deste conhecimento também é reforçada pela baixa diversidade observada de recursos naturais utilizados pelos dois Piripkura quando comparados às informações obtidas junto a Rita. Assim, considerando os relatos dos progenitores de Rita, em que entre as décadas de 40 e 80 houve significativa redução populacional dos Pirpkura, devido a conflitos perpetrados por não-índios, é plausível subtender que tais conflitos contribuíram fortemente para desestruturar a organização social do grupo e, consequentemente, o conhecimento relativo ao CET-Piripkura.

Embora a comparação das informações obtidas junto a Rita com aquelas da FPE-MJ mostre diferenças quando à diversidade de itens utilizados, é importante ressaltar que entre os dois conjuntos de dados há similaridade no que tange ao modo de vida do subgrupo de Rita com aquele dos dois Piripkura. Em outras palavras, a continuidade da perda de estratégias de uso de recursos levou os dois Piripkura a praticarem um modo de vida similar ao do subgrupo de Rita que, na década de 70 , já não dispunha de arco e flecha. Tal fato é de extrema 
relevância, pois este atual modo de vida provavelmente representa o limite de adaptação ao que o CET-Piripkura pode chegar quanto à redução na diversidade de estratégias para acessar os recursos passíveis de serem utilizados. Esta perspectiva é reforçada por pelo menos três observações. A primeira é relativa à sincronia temporal entre o baixo registro na diversidade de consumo de frutos e alta frequência de consumo de castanha e de babaçu, ano após ano, nas duas estações climáticas. A segunda vem do relato de que os Kawahíwa do Rio Pardo, habitando ambiente similar (Meio físico e biótico) e sujeitos às mesmas pressões antrópicas negativas de não-índios, também utilizam uma reduzida diversidade de recursos (Jair Candor; comunicação pessoal), sugerindo um efeito similar da desestruturação social sobre o CET de indígenas em estado de isolamento voluntário no interflúvio entre os rios Juruena e Madeirinha. A terceira está relacionada às estratégias para obter alguns recursos; no caso da castanha e do mel, os vestígios demonstram que, por vezes, o acesso aos mesmos está sendo feito derrubando árvores, fato que lhes imprime um alto gasto energético, risco de vida e, em princípio, redução do próprio recurso. Estes argumentos reforçam, num primeiro momento, que a especialização no acesso à uma pequena parcela de recursos da flora e da fauna se constitui em uma das adaptações do CET-Piripkura para a sobrevivência dos indígenas na TI-PRK no contexto delineado na figura 2.

Ainda no que concerne às práticas de manejo adaptativo do CET-Piripkura, cabe destacar o uso do espaço nas suas perspectivas geográfica e temporal. Quanto à esta última, ao se considerar a relação entre os deslocamentos anuais dos indígenas e as estações do ano, é possível subtender que eles possuem profundo conhecimento quanto à dinâmica de disponibilidade dos recursos necessários à sua sobrevivência nas microbacias dos igarapés. Isto reforça a tradicionalidade de uso e ocupação do território pelos Piripkura, na medida em que, conforme já mencionado, o conhecimento sobre o ambiente, seus recursos, onde se encontram e em que época estão disponíveis demandam, inevitavelmente, tempo de aprendizado e repasse de conhecimento (Berkes et al. 1995). Na perspectiva geográfica, a dinâmica dos vestígios demonstra tendência na ocupação de distintas bacias, conforme mostrado na figura 6 , exceção feita para os anos (2008 e 2009) em que houve maior incidência da presença de não-índios dentro do território. Esta influência no uso do espaço geográfico é ressaltada ao se considerar que na expedição realizada nos igarapés do Veado, das Rosas, dos Índios e Seis contos pela FPE-MJ, em 1990, a equipe encontrou, coincidentemente, vestígios antigos da presença dos indígenas e vestígios recentes da presença de atividades de garimpo e de extração de madeira. Adicionalmente, o aumento da frequência de uso do igarapé Duelo em 2008 e 2009 por Tikum e Monde'i coincide com a intensificação da extração de madeira e abertura de estradas por não-índios no mesmo período, nos igarapés Iãpetéga, Repartimento, Garça-do-índio e Garça-do-branco, por 
sua vez sendo utilizados pelos indígenas em 2006 e 2007. Por fim, o início da reocupação dos três últimos igarapés pelos indígenas se inicia em 2010, um ano após a publicação da Portaria de Interdição da TI-PRK em 2009, a qual, consequentemente, permitiu à equipe da FPE-MJ limitar o acesso de não-índios e das atividades de extração de madeira no território tradicional Piripkura.

A partir deste conjunto de evidências é possível compreender que o uso do espaço geográfico e e o uso do espaço temporal também constituem importantes variáveis na resiliência e adaptação do CET-Piripkura como estratégias de sobrevivência destes indígenas. Quando estas variáveis são consideradas conjuntamente com a redução observada no uso da biodiversidade e das estratégias de acesso aos recursos, é possível argumentar que a disponibilidade de espaço geográfica é imprescindível para a sobrevivência dos Piripkura. Isto decorre do fato de que a especialização em poucos recursos levou ao aumento da frequência de uso de algumas espécies (castanha, paca, cutia, jacaré e mel) ou habitats. Nesse sentido, uma das formas de se minimizar a pressão de uso sobre suas populações e/ou habitats - provavelmente o único disponível aos Piripkura - é o uso e ocupação de áreas mais extensas no tempo - sob e desce pelo leito dos igarapés - e no espaço geográfico, ou seja, uso de distintas microbracias hidrográficas.

Do ponto de vista biológico, a partir da caracterização dos meios físico e biótico da TI-PRK é possível melhor compreender a necessidade de uso de diversas microbacias para a prática propriamente dita do CET-Piripkura. A caracterização demonstra que o território apresenta hidrografia composta por uma rede de inúmeros igarapés, que seu relevo é diverso, mas com relativa padronização de ocorrência de tipos de solo determinandos e, por sua vez, da distribuição dos tipos de formações vegetais no espaço geográfico. Conjuntamente, isso favorece e/ou limita a ocorrência das espécies vegetais a regiões específicas, determinando, em última instância, o local onde o recurso vai estar disponível. Assim, para se ter acesso a diferentes recursos da fauna e da flora, bem como de suas populações é preciso fazer o uso de distintas regiões, aqui materializadas pelas microbacias dos igarapés. Por exemplo, os topos das colinas (divisa entre microbacias) favorecem a ocorrência da castanha e os fundos de vale, as palmeiras.

A totalidade de informações apresentadas nesta pesquisa ressaltou que, na atualidade, o CET-Piripkura está composto por uma parcela das práticas "originais" de manejo da biodiversidade e que sua continuidade depende, intrinsicamente, da manutenção da integridade ambiental da TI-PRK como ecossistema. Tendo como parâmetro este fato, é plausível sugerir que o CETPiripkura, muito provavelmente, já se encontra no seu limiar quanto ao conjunto de conhecimento e práticas para garantir a sobrevivência dos Piripkura. Neste sentido, subtende-se que o CET-Piripkura não conseguirá se adaptar a um novo estado de equilíbrio do ecossistema similar ao que se vê na quase totalidade do 
entorno da TI-PRK e também em alguns pontos do seu limite interno. Esta nova paisagem, composta majoritariamente por pastagens, pequenos fragmentos de vegetação natural e hidrografia em contínuo processo de assoreamento não favorece a manutenção da biodiversidade, da qual os Piripkura têm forte dependência, seja como fonte de recurso par sua sobrevivência, seja como instrumento imprescindível à manutenção do funcionamento da TI-PRK como ecossistema (Hooper et al. 2005). Assim, é urgente refletir profundamente sobre isso, na medida em que o processo de expansão econômica na região e demais áreas da Amazônia Meridional têm, historicamente, gerado intensa degradação ambiental e perda da biodiversidade.

\section{Referencias}

Azanha, Gilberto. 2006. Relatório antropológico de identificação de delimitação da Terra Indígena Kawahíwa do Rio Pardo. Relatório técnico elaborado sob a coordenação da Fundação Nacional do Índio (FUNAI). Disponível na biblioteca da Diretoria de Assuntos Fundiários da FUNAI.

Berkes, F., and Folke, C. 1998. Linking social and ecological systems for resilience and ustainnability. Pages 1 to 25 in: Berkes, F., and C. Folke, editors. 1998. Linking social and ecological systems: management practices and social mechanisms for building resilience. Cambridge University Press, Cambridge, UK.

Berkes, F., Folke, C., and Gadgil, M. 1995. Traditional ecological knowledge, biodiversity, resilience and sustainability. Pages $269-287$ in C. Perrings, K.-G. Mäler, C. Folke, C. S. Holling, and B.O. Jansson, editors. Biodiversity conservation. Kluwer Academic Publishers, Dordrecht, The Netherlands.

Brasil, 1978. Departamento Nacional de Produção Mineral (Projeto RADAMBRASIL). Volume 20 (Folha SC 20. Porto Velho): geologia, geomorfologia, solos, vegetação e uso potencial da terra $661 \mathrm{pp}$.

EPE. 2011. Avaliação ambiental integrada da bacia do rio Aripuanã (Tomo I: volume 01). Relatório técnico elaborado sob a coordenação da Empresa Brasileira de Pesquisa Energética (Ministério de Minas e Energia) no âmbito do Estudo de Inventário Hidrelétrico da Bacia Hidrográfica do rio Aripuanã. Disponível em http://www.mma.gov.br/estruturas/sqa_pnla/_arquivos/sqa_3.pdf.

Holling, C. S. 1973. Resilience and stability of ecological systems. Annual review of ecology and systematics 4:1-23.

Holling, C. S. 1986. The resilience of terrestrial ecosystems: local surprise and global change. Pages 292-317 in W. C. Clark and R. E. Munn, editors. Sustainable development of the biosphere. Cambridge university press, london, uk.

Holling, C. S., D. W. Schindler, B. H. Walker, and J. Roughgarden. 1995. Biodiversity in the functioning of ecosystems: an ecological synthesis. Pages 44-83 in c. A. Perrings, K. G. Mäler, C. Folke, C. S. Holling, and B.O. Jansson, editors. Biodiversity loss: economic and ecological issues. Cambridge university press, cambridge, uk.

Hooper, D. U., F. S. Chapin, J. J. Ewel, A. Hector, P. Inchausti, S. Lavorel, J. H. 
Lawton, D. M. Lodge, M. Loreau, S. Naeem, B. Schmid, H. Setala, A. J. Symstad, J. Vandermeer, and D. A. Wardle. 2005. Effects of biodiversity on ecosystem functioning: a consensus of current knowledge. Ecological monographs, 75(1): $3-35$.

Menéndez, Miguel. 1992. “A área Madeira-Tapajós. Situação de contato e relações entre colonizador e indígenas" In Carneiro da Cunha, M. (org.) História dos Índios no Brasil. São Paulo: Cia. Das Letras.Miller, Eurico T. 2009. A cultura cerâmica do tronco Tupí no alto Ji-Paraná, Rondônia - Brasil. Revista Brasileira de Linguística Antropológica, 1(1): 35-136. Brasília: LALI/Universidade de Brasília.

Moreira, M. L. C. \& Vasconcelos, T. N. N. 2007. Mato Grosso: solos e paisagens SEPLAN, MT. Editora entrelinhas. Cuiabá, MT. 272 p SEPLAN, MT.

Odum, Eugene. 1988. Ecologia. 434 pp. Editora Guanabara Koogan. Rio de Janeiro.

Rodrigues, Aryon Dall’Igna. 1984-1985. "Relações internas na família linguística tupiguarani” In Revista de Antropologia vols. 27/28.

Rodrigues, Aryon Dall'Igna. 2000. Hipótese Sobre as Migrações dos Três Subconjuntos Meridionais da Família Tupí-Guaraní. Anais do II Congresso da Associação Nacional de Linguística e XIV Instituto Lingüístico, pp. 15961605, Florianópolis: ABRALIN. CD-Rom.

Rodrigues, Aryon Dall'Igna \& Cabral, Ana Suelly Câmara. 2002. "Revendo a classificação interna da família Tupí-Guaraní” In Rodrigues, A. D; Cabral, A. S. A. C. (Orgs.) Atas do I Encontro Internacional do Grupo de Trabalho sobre Línguas Indigenas da ANPOLL, tomo I. Belém: Editora Universitária UFPA.

SDS/AM, 2010. Plano de gestão do mosaico de unidades de conservação do Apuí. Documento técnico elaborado sob a coordenação da Secretaria de Desenvolvimento Sustentável do Estado do Amazonas (SDS/AM). Disponível em http://www. terrabrasilis.org.br/ecotecadigital/images/abook/pdf/1sem2015/Abril/39-Plano\%20 de\%20Gestao.pdf

Verdum, Ricardo. 2012. As obras de infraestrutura do PAC e os povos indígenas da Amazônia Brasileira. Nota técnica 9. Observatório de investimentos na Amazônia (INESC. 56 pp).

Recebido em setembro de 2016

Aceito em outubro de 2016 